\title{
TRES FASES DEL CRECIMIENTO ECONÓMICO ARGENTINO
}

ALAN M. TAYLOR *

Northwestern University

\section{RESUMEN}

El empeoramiento de los resultados económicos relativos de Argentina puede atribuirse, en gran parte, a las desfavorables condiciones existentes para la acumulación de capital a partir de 1913. En la primera fase (antes de 1913) el éxito de la Belle Epoque se debió a las espectaculares tasas de acumulación. En la segunda fase (1913-década de 1930) la baja tasa nacional de ahorro limitó la tasa de acumulación de capital. En la tercera fase (década de 1930-década de 1950) se adoptó una política de sustitución de las importaciones y el precio relativo de los bienes de capital importados que eran clave experimentó una brusca subida. Ahí comenzó el retraso: al principio, debido a que el ahorro era insuficiente ahorro y, más tarde, a que los altos precios de los bienes de capital importados redujeron los incentivos para realizar actividades de inversión que son las precursoras del crecimiento.

* Este artículo se basa en mi tesis doctoral terminada en 1992 en el Departamento de Eco nomía de Harvard University y dirigida por Jeffrey G. Williamson («Argentine Economic Growth in Comparative Perspective»). Me han sido útiles los comentarios de mi comité de tesis -Brad De Long, Peter Timmer y Jeff Williamsom-y la ayuda, el aliento y las criticas de Roberto Cor tés Conde, Gerardo Della Paolera, Ezéquiel Gallo, Tulio Halperín, Marcela Harriague, Tim Hat ton, Barry Howarth, Juan Carlos Korol, Andrew Mason, Ian McLean, David Pope, Graeme Snooks, Mark Thomas, Malcolm Urquhart, Claire Waters, John Womack, Jr. y los participantes en los seminarios de Harvard University, Stanford University, California University at Berkeley, el East-West Center de la Hawaii University, la Australian National University, la University of Adelaide, la University of Melbourne, el Instituto Torcuato Di Tella, la Universidad de San Andrés, la Washington University in St. Louis, la University of Essex, el California Institute of Technology, la McGill University, las reuniones de la Cliometric Society-ASSA (enero de 1993), la Wharton School de la University of Chicago y la Northwestern University. La investigación ha sido financiada en parte por la Harvard Academy for International \& Area Studies, la Tinker Foundation, la Fundación del Hemisferio, el Center for Latin American and Iberian Studies, Harvard University, el Center for International Affairs de Harvard University, el Instituto Torcuato Di Tella de Buenos Aires y la Research School of Social Sciences de la Australian National University. 


\section{ABSTRACT}

Much of Argentina's decline in relative economic performance can be attributed to deleterious conditions for capital accumulation after 1913. In the first phase (pre1913), the success of the Belle Epoque was due to spectacular rates of accumulation. In the second phase (1913-1930s), low domestic savings rates constrained the rate of capital accumulation. In the third phase (1930s-1950s) import-substitution policies were implemented and the relative price of key imported capital goods rose sharply. Retardation ensued: at first because of insufficient saving; later because price disincentives channeled funds away from investment activities which are the precursor of growth.

\section{TRES FASES DEL CRECIMIENTO ECONOMICO ARGENTINO}

La historia del crecimiento económico argentino en el siglo $\mathrm{xx}$ constituye un caso de declive que no tiene parangón en los anales de la historia económica. Argentina, que en otro tiempo fue uno de los países más ricos del mundo y que más deprisa creció, se encuentra hoy firmemente atrincherada en las filas de los países menos desarrollados; y la Belle Époque, la edad de oro de principios de siglo, periodo de rápido crecimiento, elevado nivel cultural y sueños de continua prosperidad, no es sino un débil y lejano recuerdo para la mayoría de los argentinos. Para el historiador económico, para el economista del desarrollo e incluso para el economista internacional, el fracaso económico de Argentina constituye uno de los casos más enigmáticos de desarrollo nacional y, aunque todo el mundo coincide en que Argentina ha sufrido un declive económico relativo, pocos se ponen de acuerdo sobre su naturaleza y sus causas. En este articulo tratamos de comprender el prolongado deterioro que ha experimentado la situación económica de Argentina en los últimos cien años. En primer lugar, trataremos de fechar claramente el declive e indicar su magnitud, tema que es objeto por sí solo de un polémico debate. En segundo lugar, examinaremos por separado cada una de las tres fases principales del crecimiento económico argentino comprendidas entre 1900 y la década de 1970. El elemento central del análisis será la inestabilidad de los mercados de capitales, que en un pais como Argentina - tan escaso de capital y tan dependiente de la financiación exterior- han desempeñado un papel crucial en el desarrollo económico. En tercer lugar, reuniremos estas observaciones sobre la cronología y la naturaleza del declive económico argentino para ofrecer algunas ideas sobre las causas del fracaso económico que sufrió Argentina después de la $B e$ lle Époque. 


\section{Cien años de crecimiento económico argentino}

El crecimiento de Argentina se ha caracterizado desde principios de siglo por una expansión sin precedentes seguida de un retraso persistente. Sin embargo, la determinación del momento exacto en que comenzó el declive sigue siendo objeto de toda una variedad de interpretaciones, cada una de las cuales puede utilizarse para apoyar o socavar cualquier análisis social, político e histórico. La cuestión fundamental puede formularse de la manera siguiente: ¿comenzó el declive económico argentino en la Primera Guerra Mundial, hipótesis según la cual el retraso se inició en una fase temprana, lo cual podría implicar al sistema político liberal vigente que defendió la apertura del comercio y mantuvo una orientación hacia el exterior entre 1913 y 1929? ¿O comenzó el retraso en la Gran Depresión, hipótesis según la cual éste se produjo más tarde, lo cual podría implicar a la política de sustitución de las importaciones más orientada hacia el interior que adoptaron los gobiernos populistas y nacionalistas en las décadas de 1930, 1940 y 1950?

Carlos Díaz-Alejandro encabeza la escuela que defiende la segunda interpretación '. Este autor sostiene que la politica liberal orientada hacia las exportaciones consiguió que Argentina sorteara las dificultades de los primeros años del periodo de entreguerras y señala los respetables resultados que obtuvo Argentina en relación con Australia, que es la economía homónima de colonizadores del hemisferio sur ${ }^{2}$. Tiene la optimista opinión de que la Belle Époque llegó hasta 1929 y, citando los malos resultados posteriores, les parece muy mal la política reactiva orientada hacia el interior que caracterizó a Argentina y a tantos países latinoamericanos en la década de 1930 y en años posteriores. Existe otra escuela de pensamiento representada por Guido Di Tella y Manuel Zymelman ${ }^{3}$, quienes consideran que el vertiginoso descenso que experimentaron las tasas de crecimiento de Argentina en torno a 1913 constituye una amplia prueba de que el retraso se produjo en una fecha temprana y les parece mal la descaminada política adoptada a finales de la década de 1910 y en la de 1920 que no se adaptó al lugar que ocupaba Argentina como economía basada en las exportaciones y dependiente del exterior en un mundo que ya no se inclinaba favorablemente al co-

I Carlos Diaz-Alejandro (1988).

2 El presente ensayo sigue una rica tradición de la literatura que ha realizado un analisis comparativo de las regiones de reciente colonización, también llamadas de colonizadores, sobre todo, pero no exclusivamente, Argentina, Australia y Canadá (Fogarty, Gallo y Diéguez, 1977 Denoon, 1983; Duncan y Fogarty, 1984; Di Tella y Platt, 1985; Diaz-Alejandro, 1985; Gerardi, 1985; Schedvin, 1990; McLean, 1991). Para una visión panorámica, véase Korol (1991).

3 Guido Di Tella y Manuel Zymelman (1967; 1973). 
mercio y las finanzas internacionales. También aluden a las limitaciones con que se encontró la expansión en la Pampa, donde el agotamiento del suelo agrícola de calidad llevó a «cerrar la frontera» más o menos en esa misma época.

¿Qué teoria debemos aceptar? Como mejor se contempla la pauta general de desarrollo económico que muestra Argentina desde principios de siglo es desde una perspectiva comparativa, relacionándola con el crecimiento económico de las demás grandes economías de colonizadores (Australia y Canadá) y con el grupo de paises desarrollados que comprenden la OCDE. Hemos afirmado que la base que se utilice exactamente para realizar las comparaciones puede transmitir unas impresiones totalmente diferentes sobre el éxito del crecimiento económico argentino en los diferentes periodos Taylor ${ }^{4}$. Basta echar una ojeada al cuadro 1 para comprender el porqué. El cuadro muestra que las tres economias de colonizadores experimentaron un rápido crecimiento desde 1900 hasta 1913, en plena Belle Époque en Argentina; sin embargo, en el periodo de entreguerras, las tasas de crecimiento disminuyeron vertiginosamente, pasando de 2,47 a 0,88 por ciento, lo que representa una disminución de 1,59 puntos porcentuales. El cuadro muestra que el grado de retraso de Australia y Canadá también fue significativo. Estos retrasos fueron muy superiores a la media de la economia mundial en su conjunto. En concreto, se observa que el retraso fue mucho mayor en las economias de colonizadores que en el grupo de la OCDE, donde el retraso fue de 0,25 puntos porcentuales solamente. Si se adopta una perspectiva más general, parece sólida la tesis de Di Tella y Zymelman de que Argentina experimentó un «Gran Retraso» entre 1913 y 1929: en comparación con la gran muestra de 33 países y con el grupo de países desarrollados de la OCDE, Argentina constituye una observación atípica en lo que se refiere al retraso sufrido en el periodo de entregueras. Pero la historia no acaba ahí. Como indican las tendencias a largo plazo del PIB per cápita, a partir de 1913 Argentina se quedó cada vez más rezagada con respecto al grupo de la OCDE. A partir de 1913, es evidente un continuo retraso, que incluso se acelera después de 1929 y, de nuevo, después de 1950 (figura 1). Por otra parte, mientras que las otras economías de colonizadores comenzaron a recuperarse de los malos resultados obtenidos durante el periodo de entreguerras, Argentina no consiguió esa hazaña ${ }^{5}$. El declive económico argentino se caracteriza, pues, por un continuo retraso secular a partir de 1913 en relación con el club de paises desarrollados

4 Taylor (1992).

5 En este sentido, Diaz-Alejandro tiene razón cuando critica los malos resultados que obtuvo el pais a partir de 1929 , y es esta observación la que sustenta su crítica a las medidas de orientación hacia el interior adoptadas después de la Gran Depresión de 1929, medidas reforzadas y codificadas durante los años peronistas. 
de la OCDE, el propio club en el que Argentina aspiraba a integrarse. Visto desde esta perspectiva, la divergencia entre los niveles de renta per cápita de Argentina y de la OCDE que se observa a partir de 1913 induce a pensar que los estudiosos de la historia económica argentina deben tomar en serio la hipótesis de que el retraso comenzó en una fecha temprana. No obstante, el retraso relativo de la economia argentina fue mayor a partir de 1929 y, todavía más, a partir de 1950, lo que lleva a pensar que se deterioró el ritmo de desarrollo económico y que este deterioro se agravó con el paso del tiempo.

\section{CUADRO 1}

Crecimiento económico comparado: las economías de colonizadores, 1900-87

A. PIB per cápita (dólares internacionales, precios de 1980)

\begin{tabular}{lrrrrrr}
\hline & 1900 & 1913 & 1929 & 1950 & 1973 & 1987 \\
\hline Argentina $\ldots \ldots \ldots \ldots \ldots \ldots \ldots \ldots$ & 1.284 & 1.770 & 2.036 & 2.324 & 3.713 & 3.302 \\
Australia $\ldots \ldots \ldots \ldots \ldots \ldots \ldots \ldots$ & 2.923 & 3.390 & 3.146 & 4.389 & 7.696 & 9.533 \\
Canada $\ldots \ldots \ldots \ldots \ldots \ldots \ldots \ldots$. & 1.808 & 2.773 & 3.286 & 4.822 & 9.350 & 12.702 \\
$\quad$ OCDE & 1.817 & 2.224 & 2.727 & 3.553 & 7.852 & 10.205 \\
\hline
\end{tabular}

B. PIB per cápita (en relación con $\mathrm{OCDE}-1,00$ )

\begin{tabular}{llllllll}
\hline & 1900 & 1913 & 1929 & 1950 & 1973 & 1987 \\
\hline Argentina $\ldots \ldots \ldots \ldots \ldots \ldots \ldots \ldots \ldots \ldots \ldots \ldots$ & 0,71 & 0,80 & 0,75 & 0,65 & 0,47 & 0,32 \\
Australia $\ldots \ldots \ldots \ldots \ldots \ldots \ldots \ldots \ldots \ldots \ldots \ldots$ & 1,61 & 1,52 & 1,15 & 1,24 & 0,98 & 0,93 \\
Canadá $\ldots \ldots \ldots \ldots \ldots \ldots \ldots \ldots \ldots \ldots \ldots \ldots \ldots$ & 1,00 & 1,25 & 1,20 & 1,36 & 1,19 & 1,24 \\
\hline
\end{tabular}

C. Tasas de crecimiento del PIB per capita (\%)

\begin{tabular}{llrrr}
\hline & $\begin{array}{c}1900-1913 \\
(1)\end{array}$ & $\begin{array}{c}1913-1929 \\
(2)\end{array}$ & $\begin{array}{c}\text { Retraso } \\
(1)-(2)\end{array}$ \\
\hline Argentina $\ldots \ldots \ldots \ldots \ldots \ldots \ldots \ldots \ldots \ldots \ldots \ldots \ldots \ldots \ldots$ & 2,47 & 0,88 & 1,59 \\
Australia $\ldots \ldots \ldots \ldots \ldots \ldots \ldots \ldots \ldots \ldots \ldots \ldots \ldots \ldots \ldots$ & 1,14 & $-0,47$ & 1,61 \\
Canadá $\ldots \ldots \ldots \ldots \ldots \ldots \ldots \ldots \ldots \ldots \ldots \ldots \ldots \ldots \ldots \ldots$ & 3,29 & 1,06 & 2,23 \\
Muestra de la OCDE $\ldots \ldots \ldots \ldots \ldots \ldots \ldots \ldots \ldots \ldots \ldots$ & 1,55 & 1,27 & $0,25[0,95]^{a}$ \\
Muestra de 28 paises $\ldots \ldots \ldots \ldots \ldots \ldots \ldots \ldots \ldots \ldots \ldots$ & 1,34 & 1,02 & $0,33[0,98]^{\mathrm{a}}$ \\
\hline
\end{tabular}

- indica una media muestral; la desviación típica se muestra entre corchetes.

Notas: El panel B se ha realizado a partir del A.

Fuentes: Maddison (1989, p. 19). 


\section{FIGURA 1}

Crecimiento económico comparado de Argentina: tasa anual de crecimiento del PIB per cápita en relación con la OCDE, 1900-87

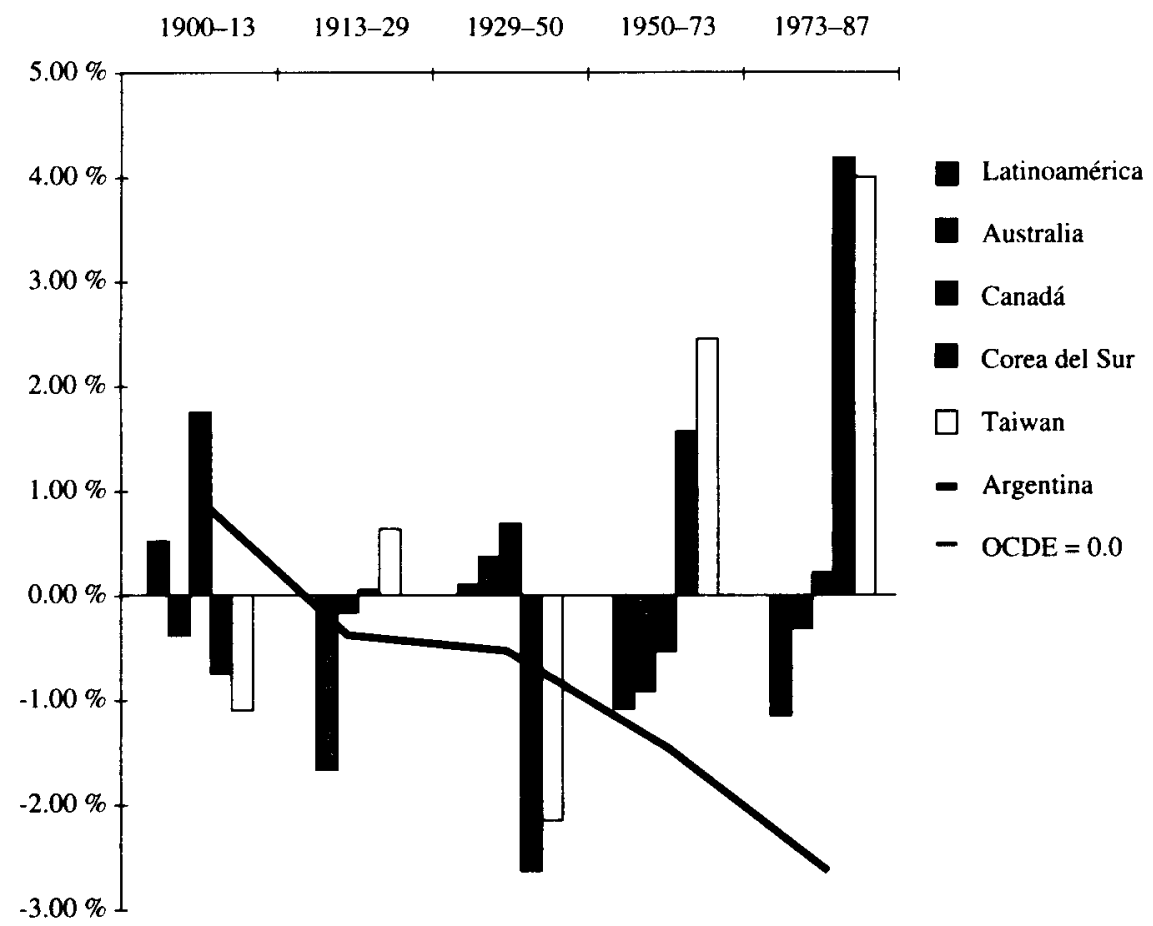

FuENTE: Maddison (1989, p. 19).

Una vez aclarada la evolución del crecimiento económico de Argentina con el análisis anterior, a continuación tratamos de identificar las causas posibles de estas distintas fases del declive económico argentino. Hay dos o tres grandes puntos de giro. La Primera Guerra Mundial fue seguida de un acusado retraso en relación con la OCDE y marcó el final de la Belle Époque según la hipótesis de que el retraso comenzó en una fase temprana: las tasas de acumulación y de crecimiento económico descendieron espectacularmente. La Gran Depresión fue testigo de un mayor retraso relativo, así como de la adopción de una variedad de medidas ad boc de orientación hacia el interior y de 
sustitución de las importaciones y de una tendencia general hacia la autarquía. Las décadas de 1940 y 1950 trajeron consigo el peronismo y el avance de la política autárquica característica de la escuela de pensamiento económico estructuralista; esa política tendió a reducir implícita o explícitamente los incentivos para la formación de capital a través de las distorsiones de los precios o de los tipos de cambio.

\section{La Belle Epoque: integración global y crecimiento}

Argentina, al igual que otras economías de colonizadores, se convirtió en una parte integral de la economía global de finales del siglo XIX, que era un sistema internacional de comercio y finanzas basado en el liderazgo británico en la banca y en el comercio que se conoce a veces con el nombre de Pax Brittanica ${ }^{6}$. Perfectamente integrado en los mercados de bienes finales, el crecimiento argentino se centró en la exportación de una pequeña gama de productos primarios, una sencilla pauta de desarrollo económico que, según se dice, podría corresponder a la «teoría de las materias primas», tipo de análisis que tiene su origen en la historia económica canadiense, pero que suele aplicarse a otros paises del Nuevo Mundo ?. Manteniendo unos acuerdos comerciales estables y teniendo la puerta abierta al capital británico que entraba libremente gracias a la estabilidad del patrón oro, Argentina prosperó en las décadas anteriores a la Primera Guerra Mundial ${ }^{8}$. Las favorables condiciones económicas que atrajeron capital extranjero también atrajeron a una enorme cantidad de emigrantes a Argentina. Algunos de los primeros colonizadores europeos de la República eran de diversa procedencia - galeses, rusos, ingleses, alemanes-, pero las grandes oleadas de las décadas de 1890 y 1890 eran esencialmente de origen mediterráneo, al principio predominantemente emigrantes del norte de Italia y, más tarde, españoles. Algunos emigraron incluso estacionalmente para trabajar tanto en los veranos del norte como en los del sur como mano de obra agricola, llevando a cabo una migra-

6 Schedvin (1990).

7 Baldwin (1956).

8 Se aplicó un freno moderado inmediatamente después de la crisis de Baring de 1890 , pero los inversores británicos pronto estuvieron dispuestos a aventurarse y a prestar de nuevo después de unos años. Como parecen indicar los escasos datos sobre la acumulación de capital, el endeudamiento exterior, el comercio y la renta nacional, los primeros años de la década de 1890 fueron un mero accidente en la tendencia de rápido crecimiento que hizo de la Argentina de la $\mathrm{Be}$ lle Époque una de las economias del mundo que creció más deprisa. 
ción flotante intercontinental sin paralelo y ganándose el calificativo de «aves de paso» ${ }^{9}$. Esta masiva migración, que representó alrededor de la mitad del crecimiento demográfico que experimentó Argentina entre 1890 y 1913, se basó indudablemente en los elevados rendimientos del reasentamiento: los altos salarios de Argentina normalmente eran el doble o el triple de los que estaban vigentes en España e Italia en aquella época, incluso ajustándolos para tener en cuenta el coste de la vida ${ }^{10}$. No debería sorprendernos, pues, la respuesta de la masiva inmigración en Argentina, fenómeno relacionado con la oferta de trabajo al que se ha sacado tanto partido en la literatura de la historia económica argentina ${ }^{11}$.

Creemos que la acumulación de factores es fundamental para comprender el crecimiento argentino de este periodo. La situación inicial de Argentina se caracteriza, al igual que la de todas las economías de colonizadores, por una escasez doble de trabajo y de capital en relación con un tercer factor abundante, los recursos. Dada la abundante entrada de factores móviles, en forma de capital extranjero y de grandes inmigraciones, por no hablar de las elevadas tasas de fecundidad y de aumento natural de la población nativa, Argentina acumuló rapidísimamente escaso capital y trabajo, por lo que pudo intensificar la utilización de capital y trabajo en la explotación de sus recursos ${ }^{12}$. El cuadro 2 muestra la pauta general de acumulación de factores en Argentina durante este periodo. La población creció a toda velocidad, pasando de una cifra inicial de 3,3 millones en 1890 a un total de 7,5 millones en 1913, experimentando una tasa anual de crecimiento de 3,5 por ciento. Alrededor de la mitad de este aumento se debió a la inmigración y la mitad al aumento natural. Sin embargo, la acumulación de capital se produjo a un ritmo aún más notable, superando al crecimiento de la población, al crecer a una tasa anual de 4,8 por ciento. La proporción del stock de capital que era de propiedad extranjera aumentó acusadamente durante este periodo, pasando de 32 por ciento en 1900 a 41 por ciento en 1909 y alcanzando la cifra de 48 por ciento en 1913 , lo que da muestra del papel fundamental que desempeñó el capital extranjero en el proceso de acumulación de Argentina. Creemos, pues, que la estrategia de crecimiento se basó en una prolongación de las favorables condiciones de los mercados internacionales de bienes y de factores, tanto en Argentina como en otros países de Latinoamérica ${ }^{13}$.

\footnotetext{
9 Bunge y Garcia Mata (1931), Cortés Conde (1979).

10 Williamson (1991), Taylor (de próxima aparición).

11 Diaz-Alejandro (1970), cap. 1; Gerardi (1985).

12 Nurkse (1954), Diaz-Alejandro (1970) y McLean (1990).

13 Cortés Conde (1992).
} 


\section{CUADRO 2}

Acumulación de factores: Argentina y Australia, 1890-1939

\section{A. Población}

\begin{tabular}{ccccc}
$\begin{array}{c}\text { Población } \\
\text { inicial }\end{array}$ & $\begin{array}{c}\text { Tasade } \\
\text { crecimientode } \\
\text { la población }\end{array}$ & $\begin{array}{c}\text { Inmigración } \\
\text { neta }\end{array}$ & $\begin{array}{c}\text { Aumento } \\
\text { natural }\end{array}$ & $\begin{array}{c}\text { Proporción } \\
\text { debida a la } \\
\text { inmigración }\end{array}$ \\
\hline
\end{tabular}

\section{Argentina}

$\begin{array}{rlrrrrr}1890-1913 & \ldots \ldots & 3,377 & 3,5 \% & 1,922 & 2,183 & 47 \% \\ 1913-1929 & \ldots \ldots & 7,482 & 2,8 \% & 0,630 & 3,633 & 15 \% \\ 1929.1939 & \ldots \ldots & 11,745 & 1,8 \% & 0,014 & 2,295 & 0,6 \%\end{array}$

Australia

\begin{tabular}{ccccccc}
$1890-1913$ & $\ldots \ldots$ & 3,107 & $1,9 \%$ & 0,319 & 1,395 & $19 \%$ \\
$1913-1929$ & $\ldots \ldots$ & 4,821 & $1,8 \%$ & 0,282 & 1,293 & $18 \%$ \\
$1929-1939$ & $\ldots \ldots$ & 5,396 & $0,9 \%$ & 0,001 & 0,574 & $0,2 \%$ \\
\hline
\end{tabular}

\section{B. Capital}

$\begin{array}{cccc}\text { Stock de } & \text { Tasade } & \text { Capital inicial } & \text { Proporción inicial } \\ \text { capital inicial } & \text { crecimiento del } & \text { depropiedad } & \text { depropiedad } \\ \text { stock de capital } & \text { extranjera } & \text { extranjera }\end{array}$

\section{Argentina}

1890-1913

478

1.450

1913-1929

1929-1939

$4,8 \%$
$2,2 \%$
$1,1 \%$

704

659

\section{$48 \%$}

$32 \%$

\section{Australia}

\begin{tabular}{llllll}
$1890-1913$ & $\ldots \ldots \ldots \ldots \ldots \ldots$ & 1.099 & $1,9 \%$ & - & - \\
$1913-1929$ & $\ldots \ldots \ldots \ldots \ldots$. & 1.713 & $2,3 \%$ & 344 & $20 \%$ \\
$1929-1939$ & $\ldots \ldots \ldots \ldots \ldots$ & 2.470 & $1,2 \%$ & 545 & $22 \%$ \\
\hline
\end{tabular}

Noras: Población en millones. Capital en millones de libras, precios de 1910. Las tasas de crecimiento han calculado a partir de los stocks. El aumento natural de la población es el aumento de la población menos la inmigración neta. La proporción debida a la inmigración es la inmigración neta dividida por el aumento de la población. El stock de capital de propiedad extranjera se ha calculado multiplicando la proporción de propiedad extranjera por el stock total $o$ viceversa.

FUENTE: Taylor (1992). 
Hemos de hacer aquí una observación cualitativa: la dependencia externa ${ }^{14}$. Argentina fue víctima de su dependencia de la senda, es decir, su estrategia de crecimiento había fomentado una rápida expansión de la población por medio de una masiva inmigración y las elevadas tasas de aumento natural de la población nativa. Al ser relativamente bajas las tasas de ahorro de Argentina, la acumulación y el crecimiento económico continuos del pais dependian del capital extranjero, precaria situación que podría explicar el comienzo del retraso argentino en la época de la Primera Guerra Mundial.

\section{Los primeros años del periodo de entreguerras: la autarquía forzosa y el retraso}

La gran expansión de la Belle Époque llegó a su fin como consecuencia de las graves perturbaciones que sufrieron las relaciones económicas internacionales como consecuencia de la Primera Guerra Mundial y de sus secuelas. La consecuencia inmediata de la guerra para los mercados internacionales fue la repentina disminución del volumen de comercio exterior y el empeoramiento, igualmente acusado, de la relación real de intercambio, debido en gran parte a la interrupción casi total del transporte maritimo por el Atlántico. La relación real de intercambio de Argentina empeoró alrededor de un 50 por ciento entre 1912 y 192115 .

Las perturbaciones también fueron evidentes en los mercados internacionales de factores. Tal vez el cambio más espectacular se registrara en el funcionamiento de los mercados internacionales de capitales. Con el estallido de las hostilidades, Gran Bretaña interrumpió el funcionamiento del patrón oro y tardó diez años en poder restablecerlo. Así acabó la era del gran imperialismo, durante la cual el capital británico, actuando desde su centro de poder en los mercados londinenses de capitales, podía dejar sentir su influencia en todo el mundo ${ }^{16}$. El poder hegemónico de Gran Bretaña en los mercados de capitales quedó destruido, de hecho, como consecuencia de las enormes deudas con-

${ }_{14} \mathrm{El}$ argumento de la dependencia exterior se ha analizado más detalladamente en otra parte (Taylor, 1992) y se resume aqui para situarlo en el contexto de una descripción del declive económico argentino a muy largo plazo. El argumento sigue una larga tradición de exploración de los determinantes demográficos del ahorro nacional y de los flujos internacionales de capital en las economías de colonizadores, sobre todo Australia (Butlin, 1962; Hall, 1968; Edelstein, 1982; McLean, 1991). Su aplicación a Argentina en forma cuantitativa es una novedad.

15 Di Tella y Zymelman (1967), Díaz-Alejandro (1970). En Australia, la relación real de intercambio disminuyó alrededor de un 35 por ciento durante el mismo periodo (Bambick, 1970).

16 Edelstein (1981), Edelstein (1982). 
traidas durante la guerra, y ahora los nuevos «banqueros del mundo» eran los americanos, que comenzaron a ser acreedores netos; sin embargo, a los americanos no les entusiasmaba precisamente la idea de asumir esta nueva responsabilidad como centro financiero internacional y el surgimiento de Nueva York como mercado de capitales verdaderamente internacional fue algo lento y reacio ${ }^{17}$. Eso fue lo que ocurrió, ciertamente, desde la perspectiva argentina y los relatos de los observadores contemporáneos confirman las dificultades con que se encontró Argentina para tratar de conseguir capital extranjero tras el estallido de la guerra y para adaptarse al cambio que suponía la desaparición de una relación consolidada con prestamistas londinenses con experiencia y la forja de nuevas relaciones crediticias con los banqueros de Nueva York ${ }^{18}$. Peters y Phelps señalan ambos el limitado acceso que comenzó a tener Argentina al capital extranjero a partir de $1913^{19}$. Hasta mediados de la década de 1920, apenas salió capital de la asolada Europa y los escasos préstamos procedentes de Nueva York requerian largas negociaciones, eran de cuantía limitada y de corto vencimiento y tenían unos tipos de interés mucho más altos que los vigentes anteriormente.

La evidencia cuantitativa confirma esta idea y hay otras fuentes independientes que, aunque se basan en datos históricos bastante frágiles, confirman la idea de que Argentina se encontró con una mayor escasez de capital en el periodo de entreguerras. Por ejemplo, la inversión extranjera casi desapareció a partir de 1914 y desde entonces hasta medidados de los años 20 los aumentos reales netos del stock de capital se financiaron por medio del ahorro nacional (figura 3). Cuando se consiguieron finalmente nuevos créditos, éstos fueron principalmente el resultado de una expansión de la participación de Estados Unidos en la base de capital argentino, sin que apenas contribuyeran los gran-

17 Kindleberger (1986).

18 La experiencia argentina constrasta claramente con la de Brasil, donde no se produjo un retraso en la transición al periodo de entreguerras (figura 2). La facilidad con que Brasil fue capaz de desarrollar unas relaciones comerciales duraderas con Estados Unidos y conseguir préstamos ampliando las relaciones financieras puede ser un factor importante en este caso. El hecho de que históricamente Argentina recurriera a los fondos británicos fue un impedimento y tuvo mucho que ver con las pautas comerciales. Brasil exportaba café desde hacía tiempo a Estados Unidos, desarrollando lazos comerciales; las principales exportaciones de Argentina, la carne de vacuno y el trigo, también eran exportaciones de Estados Unidos, por lo que tenía relaciones comerciales con los importadores de carne de vacuno y cereales del Viejo Mundo, sobre todo Gran Bretaña. Abreu analiza extensamente las diferencias entre los efectos de la política británica y la americana con respecto a Argentina y a Brasil y señala que Brasil también se benefició de la disposición de Estados Unidos a no sacar el máximo provecho en las relaciones bilaterales, lo que contrasta claramente con las relaciones comerciales anglo-americanas existentes en aquella época (Abreu, 1984).

19 Peters (1934) y Phelps (1938). 


\section{FIGURA 2}

Retraso de la economía mundial en el periodo de entreguerras

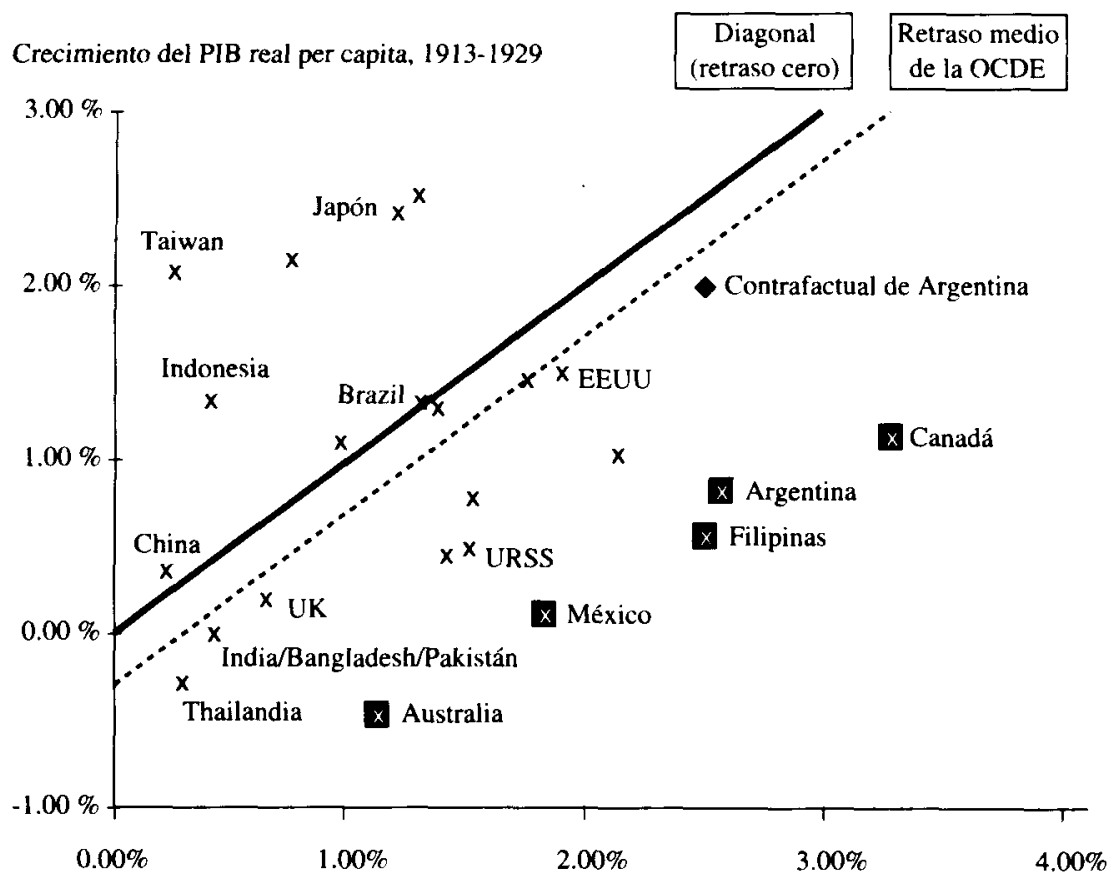

Crecimiento del PIB real per capita, 1900-1913

Notas: Los paises de la Europa continental no se indican por razones de claridad.

Fuente: Maddison (1989, p. 19).

des prestamistas europeos anteriores. Por otra parte, la caracterización de la escasez de capital es válida tanto desde el punto de vista de los precios como desde el punto de vista cuantitativo. El examen de las tendencias de los tipos de interés reales de los bonos argentinos emitidos en el extranjero a partir de 1900 revela que el coste real de los créditos experimentó un enorme incremento durante la Primera Guerra Mundial y que los tipos de interés reales subieron de alrededor de un 3,6 por ciento, en promedio, entre 1900-1913 a alrededor de un 5,7 por ciento, en promedio, entre 1914 y 1929 (figura 4). Así pues, cuando desaparecieron los créditos extranjeros, Argentina se encontró 


\section{FIGURA 3}

\section{El capital extranjero en Argentina, 1910-34}

Millones de pesos de oro

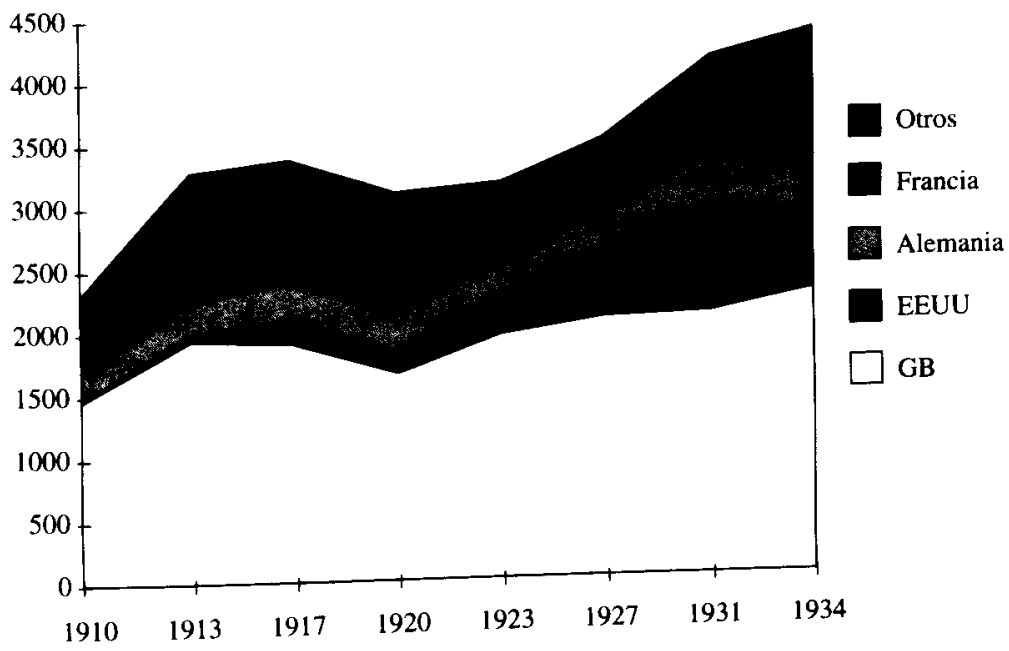

FuENTE: Gerardi (1985, p. 46).

con que la oferta limitaba la acumulación de capital, por lo que tuvo que recurrir más a su relativamente débil capacidad de ahorro interior para financiar la inversión ${ }^{20}$.

Como consecuencia del nuevo orden existente en los mercados de capitales, la acumulación de capital de Argentina comenzó a verse limitada en gran medida por su ahorro, pero su capacidad de ahorro era notablemente baja, a juzgar por el retraso de sus tasas de acumulación. La tasa anual de crecimiento del stock de capital de Argentina cayó de 4,8 por ciento en el periodo 1890 1913 a 2,2 por ciento solamente en el periodo 1913-1929 (cuadro 2). Este cam-

20 Nos encontramos ante un problema de identificación: ¿disminuyó la inversión argentina debido a perturbaciones de la oferta de ahorro o a una disminución repentina de la rentabilidad de la inversión? Podemos deducir que el retraso se debió en gran medida a las perturbaciones de la oferta (de ahorro) de capital más que a las perturbaciones de la demanda de inversión, ya que el coste real de los créditos (el precio) aumenta después de la perturbación. Los datos sobre pues, a identificar la causa de las perturbaciones, tal como revelan las variaciones de las cantidades. 


\section{FIGURA 4}

Tipos de interés reales: Argentina, 1900-39

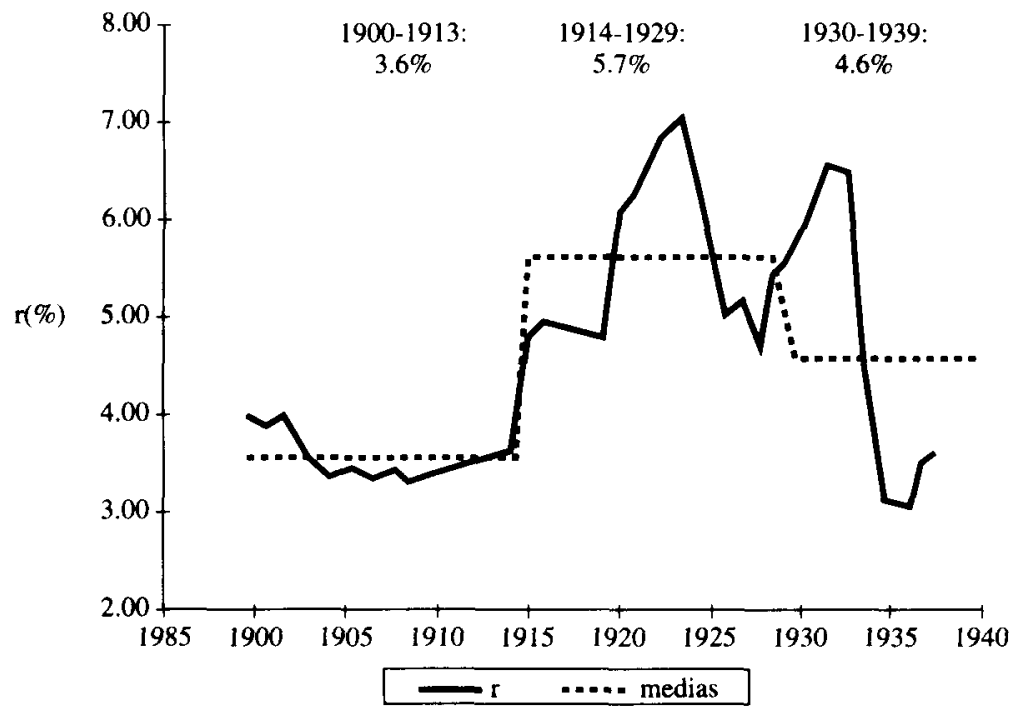

NOTAS: La variable $r$, que es el tipo de interés real argentino esperado (ex ante), corresponde a los bonos emitidos en el extranjero y se calcula de acuerdo con la formula $r=i-\pi^{e}+d e / d r$, donde $i$ es el tipo de interés nominal de los bonos, $\pi^{e}$ es la tasa de inflación argentina esperada (media movil quinquenal retardada) y $d e / d t$ es la tasa esperada de depreciación (media móvil quinquenal retardada). Hasta 1913, la mayoria de los bonos se emitian en Londres y $d e / d t=0$, ya que el peso y la libra tenian paridades fijas conforme al patrón oro. A partir de 1913, la mayoria de los bonos se emitian en Nueva York y $d / d t^{*}$ reflejaba las variaciones del tipo de cambio entre el peso y el dólar. Las medias de los periodos se muestran por medio de las líneas de trazo discontinuo y su valor se indica en la parte superior de la figura.

FUENTES: Los tipos de interés nominales de los bonos emitidos en el extranjero proceden de Homer y Sylla (1991) y Peters (1934). La tasa de inflación basada en el nivel de precios de la producción procede de IEERAL (1986) y Della Paolera (1988). Los tipos de cambio proceden de IEERAL (1986) y Tornquist (1919).

bio de régimen también se observa en las tasas de crecimiento del PIB per cápita, que descendieron de 2,47 por ciento al año en $1900-13$ a 0,88 por ciento en 1913-29 (cuadro 1). A pesar de la grave crisis de los mercados de capitales y del retraso de la economía, la inmigración se reanudó al terminar la guerra y siguió contribuyendo al crecimiento de la población ${ }^{21}$. Así pues, aunque la in-

21 Entre 1919 y 1939, Argentina tuvo una tasa neta de inmigración de 3,9 por ciento, lo que representa un 17 por ciento del crecimiento de la población; entre 1920 y 1939, Australia tuvo una tasa neta de inmigración de 3,1 por ciento, lo que representa un 22 por ciento del crecimiento de la población. 
migración argentina había disminuido considerablemente desde las grandes oleadas de la Belle Époque, continuó siendo una fuerza persistente. Aunque los mercados de capitales sufrieron una enorme reorganización y los préstamos extranjeros concedidos a Argentina se redujeron a casi nada, los mercados internacionales de trabajo se recuperaron algo después de la guerra. Las «aves de paso" se convirtieron en algo del pasado, pero el crecimiento de la población argentina iba a seguir siendo bastante rápido en el periodo de entreguerras y a ser de un 2,37 por ciento al año en el periodo 1919-1929 debido en parte a la continua inmigración ${ }^{22}$.

Asi pues, podría culparse a la baja capacidad de ahorro de las bajas tasas de acumulación de capital, de intensificación del capital y de crecimiento económico. Es lógico preguntarse a qué se debia esta baja capacidad de ahorro. Está fuera del alcance de este artículo explicar totalmente las causas, pero en otro trabajo hemos demostrado que el ahorro argentino fue bajo en los primeros años de este siglo, al menos cuando se compara con las tasas de ahorro de Australia y Canadá ${ }^{23}$. Mientras que tanto Australia como Canadá ahorraron alrededor de un 15 por ciento del PIB entre 1900 y 1929, Argentina sólo ahorró alrededor de un 5 por ciento. Hemos afirmado que esta capacidad relativamente baja de ahorro podría atribuirse en gran parte a la peculiar estructura demográfica de Argentina: la evidencia econométrica parece indicar que existia una estrecha y significativa relación entre las tasas de dependencia y las tasas de ahorro, y Argentina tenía una tasa de dependencia unos cuantos puntos superior a la de Australia y Canadá, característica que iba a persistir hasta bien entrado el siglo $\mathrm{xx}^{24}$. En una situación demográfica más favorable - una distribución por edades australiana o canadiense utilizada como contrafactuallas tasas de ahorro y de crecimiento de Argentina casi se habrian duplicado en el periodo de entreguerras y el retraso con respecto a los paises de la OCDE se habría reducido extraordinariamente ${ }^{25}$. Un experimento contrafactual de

22 Taylor (1992).

23 Taylor (1992).

24 Las tasas de dependencia eran nada menos que del 40,1 por ciento en Argentina en 1895, del 37,1 por ciento en Australia en 1891 y del 36,4 por ciento en Canadá en 1891. Las causas de esta diferencia entre las tasas de dependencia podrian ser múltiples. Las tasas más altas de fecundidad de Latinoamérica tendian a producir unas tasas de aumento natural más altas y, normalmente, unas familias más numerosas: las tasas de fecundidad de Argentina y las principales regiones de Italia y España, de donde procedían los inmigrantes, normalmente eran de treinta y tantos por mil; en Australia, al igual que en Inglaterra y Gales, giraban en torno a veintitantos por mil. Las tasas (por mil) eran en el periodo 1910-14 las siguientes: Argentina, 37,9; Italia, 32,0; Australia, 27,8; Inglaterra y Gales, 24,2 (Mitchell, 1980; Mitchell, 1983).

25 La «carga demográfica» desempeñó un papel mucho mayor en la atracción de capital ex tranjero en Argentina que en Australia o en Canadá (Taylor y Williamson, 1994). 
ese tipo es ciertamente compatible con la observación más general que hemos hecho en este artículo, a saber, que la causa inmediata del retraso que experimentó Argentina alrededor de la Primera Guerra Mundial fue la interrupción repentina de la corriente continua de financiación exterior británica que habia garantizado las masivas acumulaciones de capital durante la Belle Epoque.

\section{El peronismo y el legado de la Gran Depresión: la política reactiva, la codificación y las distorsiones}

En 1929 resurgieron los peligros de la dependencia exterior en la economía argentina, pero en esta ocasión con un efecto mucho más duradero. El orden liberal había sobrevivido a las presiones de la guerra, habia mantenido el statu quo comercial y financiero en Argentina durante la Primera Guerra Mundial y en la década de 1920 y había continuado poniendo énfasis en el comercio exterior y en la relación con la economía internacional. Sin embargo, al hacerse sentir la Depresión, Argentina soportó la retirada de capital americano y su exclusión de las preferencias comerciales imperiales y los acontecimientos políticos tomaron su propio rumbo ${ }^{26}$. Argentina emprendió un viaje hacia una mezcla de nacionalismo y proteccionismo económico que iba a generar toda una filosofía económica y a crear las condiciones propicias para la aparición de la pareja política más conocida de Argentina ${ }^{27}$.

En términos económicos muy generales, la intervención en todos los terrenos transformó la economía, que dejó de ser una pequeña economía abierta y orientada hacia el exterior para convertirse en un pais de «industrias infantiles», que trataba de dejar de depender de las vicisitudes del comercio mundial.

26 Argentina es en numerosos aspectos una excepción en lo que se refiere a la recuperacion económica a partit de 1929 en Latinoamérica. No sólo adoptó una politica reactiva relativamente suave, sino que, una vez más, pagó un alto precio por un paquete de exportaciones y préstamos que todavia estaba muy sesgado hacia los mercados británicos de bienes y de capitales (Thorp, 1992). Una vez más, debemos recordar la importante idea de Abreu sobre la débil posición negociadora de Argentina, cuyo comercio exterior y la orientación de sus inversiones estaban dominados por Gran Bretaña (Abreu, 1984).

27 Desde finales del siglo xIx, los argentinos habian sido testigos de una sucesión de pacíficas transiciones de un gobierno civil a otro, comprometidos todos ellos más o menos a preservar la posición económica de Argentina como exportadora periférica de bienes primarios, intimamente ligada a los mercados mundiales. Los regímenes militares que siguieron a la caída del gobierno radical de Hipólito Yrigoyen en 1930 decidieron llevar a Argentina por un camino político y económico diferente. El nuevo orden que establecieron colocó los intereses nacionalistas y militares en un primer plano del debate político, donde iban a permanecer incluso hasta nuestros dias. 
El objetivo era la autosuficiencia en el sector industrial y manufacturero bajo la protección de una estrategia de sustitución de las importaciones y de orientación hacia el interior. Por otra parte, el abandono de las restricciones que imponía el patrón oro recién restablecido permitió disociarse totalmente de la economia mundial y adoptar libremente ambiciosas medidas keynesianas, tanto fiscales como monetarias, en un intento de sacar a la economía de las profundidades de la Depresión. Este espectacular cambio de rumbo de la política económica argentina no tuvo nada de extraordinario: estos cambios políticos y económicos eran la regla, más que la excepción, en toda Latinoamérica ${ }^{28}$.

La Depresión fue seguida inmediatamente por la Segunda Guerra Mundial, que sólo sirvió para reforzar la postura aislacionista de Argentina en la economía mundial. El volumen de comercio, ya reducido por la Depresión, casi desapareció con la reanudación del bloqueo del transporte marítimo. El retorno a la autarquía, sin embargo, concordó perfectamente con la nueva estrategia económica argentina, que brindaba más posibilidades para adoptar una orientación hacia el interior, protegerse de la competencia extranjera y mejorar aún más el desarrollo industrial. A principios de los años $50, \mathrm{Ar}$ gentina llevaba casi veinte años desarrollándose hacia dentro y mantenía una inmensa variedad de aranceles, protecciones y otros elementos de intervención del Estado en la economía ${ }^{29}$. Sin embargo, el factor que dio un nuevo giro al equilibrio político y económico fue la llegada al escenario de Juan y Eva Perón. El programa peronista, al que se opuso el gobierno vigente, consistía en situar la intervención del Estado en un plano más importante y fijarse como objetivo la mejora de la clase obrera. El nuevo régimen reforzó el papel del Estado en la economía: más programas de nacionalización de las empresas de servicios públicos, siderurgia y banca; una expansión de las juntas de comercialización y de otros organismos reguladores; un decidido esfuerzo por elevar los salarios reales; una ampliación de los programas sociales, incluidos los sistemas de pensiones. Estas medidas eran un punto

28 Seria razonable afirmar que la lucha por la autosuficiencia fue un éxito para los países de esta región. Sus economias sufrieron unas perturbaciones relativamente moderadas durante la Depresión y a menudo se piensa que este alejamiento de las graves penurias que padecieron Norteamérica y Europa se debió precisamente a la política de desvinculación que se adoptó (Díaz-Alejandro, 1970; Díaz-Alejandro, 1984b; Duncan y Fogarty, 1984; Maddison, 1985). Aun asi, la contribución mensurable de la sustitución de las importaciones a la recuperación de Latinoamérica en la década de 1930 parece poco importante y la recuperación de las exportaciones desempeñó un papel clave, alimentada por la devaluación general (Campa, 1990; Thorp, 1992; Bulmer-Thomas, 1994, de próxima aparición).

29 Diaz-Alejandro (1984a). 
de partida radical para la mayoria de los argentinos, y no estuvieron exentas de costes ${ }^{30}$.

\section{La inversión y el crecimiento económico: algunas perspectivas cuantitativas}

Las implicaciones para la acumulación de capital de estos veinticinco años de progresivo aislamiento económico son profundas y merecen un detallado análisis por si mismas. Dadas las dificultades anteriores para la acumulación de capital, la adopción de una política reactiva y el compromiso con la interven. ción del Estado que fue el legado de la Gran Depresión da una idea de los continuos obstáculos con que se encontró la inversión argentina, la intensificación del capital y el crecimiento económico; esta relación ha sido destacada en el caso de Argentina con mayor elocuencia por Diaz-Alejandro ${ }^{31}$ y se ha ofrecido como diagnóstico en otros países latinoamericanos durante el periodo de la posguerra ${ }^{32}$. A continuación pretendemos sistematizar, desarrollar y cuantificar la tesis de Díaz-Alejandro realizando un análisis econométrico para explicar las tasas relativamente bajas de formación de capital que se registraron en Argentina durante las décadas de 1950 y 1960 . El modelo se basa en un análisis de datos de corte transversal de la demanda de inversión de un gran número de países, en los que los sistemas intervencionistas se caracterizan por el elevado precio relativo del capital provocado por el racionamiento, los controles $\mathrm{u}$ otras distorsiones.

Las intervenciones en el mercado de capitales constituyen una grave amenaza para la acumulación eficiente y un crecimiento económico continuo. Algunas medidas, como el racionamiento de las divisas, tienden a producir nocivos efectos en este sentido. Normalmente, se concede una gran prioridad y, por lo tanto, abundantes divisas a los bienes de consumo importados y a las

${ }^{30}$ Los costes a corto plazo pudieron apreciarse en seguida. El déficit público aumentó inmediatamente, la presión para conseguir créditos había drenado las reservas de divisas y el recurso de la emisión de dinero habia disparado la tasa de inflación. La presión era demasiado grande para soportarla, y en 1952 Perón tenía dificultades. El apoyo populista de la clase obrera disminuyó al reducirse sus ganancias anteriotes como consecuencia de la congelación salarial y se endurecieron los controles de divisas para frenar la pérdida de reservas. Durante los últimos años de la presidencia de Perón, antes de su derrocamiento en el golpe de estado de finales de 1955 , se abandonó el dogma imperialista, se hizo una llamada a la inversión extranjera y se negaron las promesas populistas anteriores (Diaz-Alejandro, 1970; Duncan y Fogarty, 1984, págs. 53-55; Prebisch, 1984; Prebisch, 1986).

${ }_{11}$ Diaz-Alejandro (1970).

32 Cardoso y Fishlow (1992). 
materias primas importadas, a los primeros porque debe mantenerse el principio «panem et circenses» para tener garantizado el apoyo popular y a las segundas porque sin los factores vitales, tendría que cesar la producción en numerosas industrias. De esta forma, se sacrifica la eficiencia dinámica para perpetuar una asignación estática ineficiente: el racionamiento de las divisas restantes, utilizadas para comprar bienes de capital importados, hace que el tipo de cambio de los bienes sea desfavorable en estas categorias. Por lo tanto, una subida del precio relativo de los bienes de capital es un corolario común de un sistema de tipos de cambio múltiples. La consecuencia de esa distorsión de los precios es totalmente predecible: el aumento del coste de la maquinaria y del equipo provoca una disminución de la formación de capital en estos bienes. El entorno que acabamos de describir encaja casi perfectamente en la Argentina posterior a la Segunda Guerra Mundial. (Diaz-Alejandro describe extensamente la espectacular subida que experimentó el precio de los bienes de capital a partir de 1935 y durante toda la década de 1960) ${ }^{33}$. Los precios de las principales categorías de absorción mostraron unas tendencias muy diferentes durante este periodo: los precios de los bienes de consumo bajaron alrededor de un 10 por ciento en relación con el deflactor del PNB después de la guerra, pero los precios de los bienes de capital subieron, por lo general, entre un 40 y un 60 por ciento. Los bienes de equipo fueron uno de los componentes de la inversión cuyo precio relativo subió más que la media: entre un 60 y un 100 por ciento más que el deflactor del PNB (cuadro 3). Lo que ocurrió con las tendencias de los precios con el paso del tiempo en Argentina también ocurrió con los niveles de precios internacionales en comparación con Argentina. La Comisión Económica para América Latina (CEPAL) recogió datos sobre las estructuras de los precios de 1962 y observó que el precio relativo de la nueva maquinaria y equipo era entre 2,5 y 3,3 veces más alto en Buenos Aires que en dos grandes ciudades de Estados Unidos ${ }^{34}$.

33 Las distorsiones eran tan grandes que los efectos de los precios relativos distorsionaron la contabilidad nacional argentina durante el periodo 1944-65; por ejemplo, la proporción que representa la inversión con respecto al PIB, medida a precios de 1935-38, sólo es de un 13 por ciento, cifra no muy diferente de la de 12 por ciento registrada en 1935-41; a precios corrientes, el porcentaje es del orden del 20 por ciento (Díaz-Alejandro, 1970, cap. 6, pág. 309).

34 Diaz-Alejandro (1970), pág. 318. Este resultado es coherente con las diferencias existentes entre las tendencias de los precios relativos en el periodo 1935-62 en cada pais; partiendo de proyecciones retrospectivas aproximadas, Diaz-Alejandro estima que en Buenos Aires el precio relativo de la nueva maquinaria y equipo era de 176 en 1935.38 y de 254 en 1962, tomando como referencia igual a 100 el precio de Houston y de Los Angeles en 1962 (Díaz-Alejandro, 1970, paig. 525). 


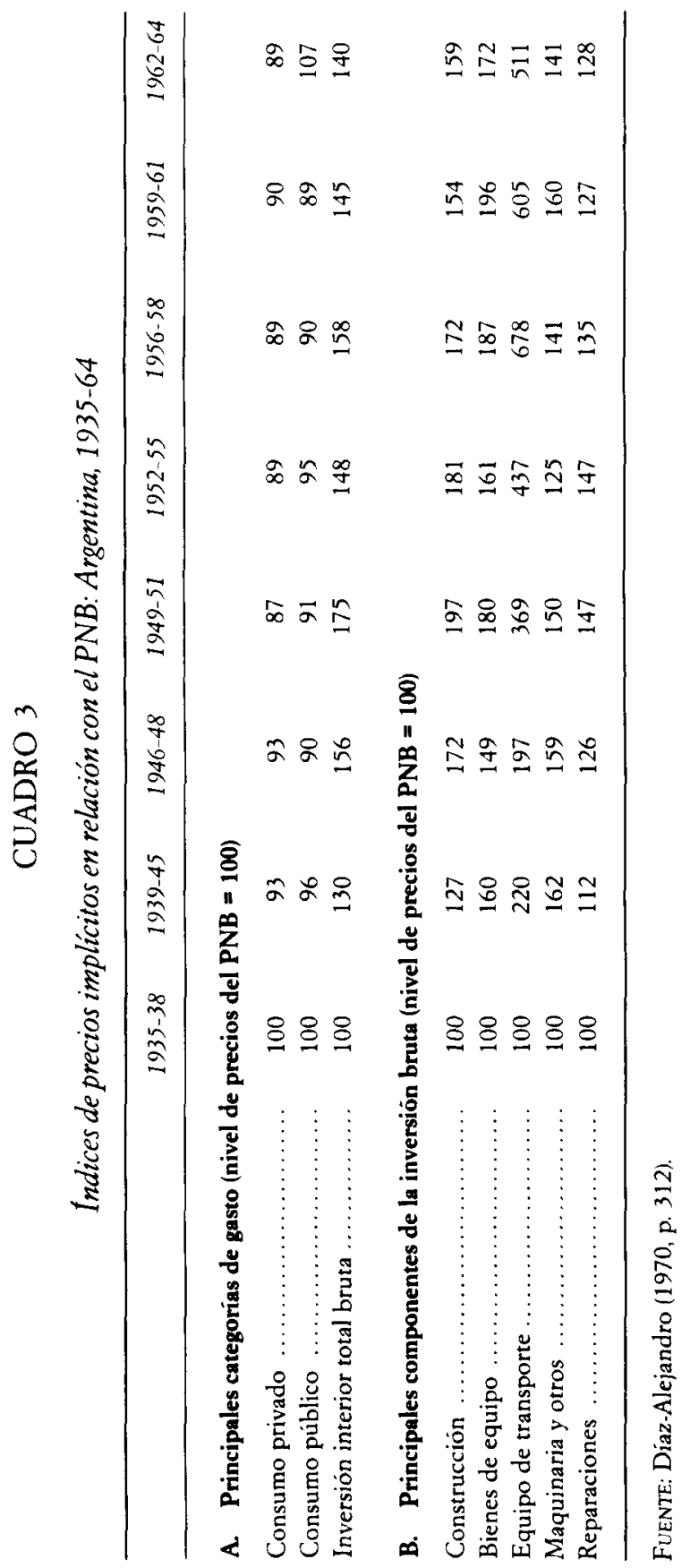


Se acusó a la restricción de las importaciones de una gran parte la subida de los precios relativos de los bienes de capital. En 1959, los aranceles medios sobre las importaciones oscilaban entre el 78 y el 130 por ciento ad valorem, mientras que en $1935-38$ eran del orden de un 30 por ciento. Basta un cálculo aproximado para ver que un índice de precios de los bienes de capital que en 1935-38 fuera igual a 100 aumentaría a alrededor de 150 únicamente como consecuencia de estos aranceles ${ }^{35}$. Aunque la incidencia exacta de los aranceles es ambigua en este periodo, es cierto que una gran parte de la subida que experimentó en la posguerra el precio relativo de los bienes de capital comerciables se debió directamente a una ampliación de uno u otro tipo de restricciones de las importaciones ${ }^{36}$. Al mismo tiempo, la disminución de la productividad del trabajo y las consiguientes subidas de los precios relativos aquejaron a la producción de bienes de capital no comerciables, como las estructuras. Diaz-Alejandro llega a la conclusión de que

[a] unque los datos dejan mucho que desear, apenas hay duda de que los precios de los bienes de capital subieron significativamente en relación con el deflactor del PNB a partir de 1935-38. También subieron en relación con los precios de otros bienes no rurales. Los precios de los bienes de equipo fueron los que más subieron. Como consecuencia, los precios de los bienes de capital argentinos han alcanzado unos niveles mucho más altos que los de la mayoría de los demás paises. Aunque no existe ninguna causa que explique estas tendencias de los precios, la escasez de divisas y la disminución de la productividad del trabajo en la construcción constituyen una explicación satisfactoria ${ }^{37}$.

La influencia del precio relativo de los bienes de capital en la determinación de las tasas de formación de capital y de crecimiento económico está bien fundamentada tanto en los estudios históricos del desarrollo como en los contemporáneos. El estudio de Williamson y Lindert sobre el ahorro y la inversión en los Estados Unidos del siglo XIX induce a pensar que el descenso del precio relativo de los bienes de capital desempeña un papel fundamental en la

35 Consideremos el caso de una subida de un arancel ad valorem de 30 a 100 por ciento sobre los bienes de equipo cuyo precio es 100 . El precio al por menor subiria de 130 a 200 , lo que supondría una subida del 54 por ciento, ceteris paribus. De hecho, los bienes de equipo subieron de precio un 96 por ciento entre 1935-38 y 1959-61 (cuadro 3). Por lo tanto, los aranceles sobre las importaciones explican por sí solos más de la mitad de la subida del precio relativo de esos bienes. Por alguna razón, Díaz-Alejandro exagera esta cifra para sugerir que la subida de los aranceles podría representar una subida de los precios de un 150 por ciento (Díaz-Alejandro, 1970, pág. 327).

36 Diaz-Alejandro (1970), p. 327.

37 Díaz-Alejandro (1970), p. 310. 
espectacular subida de las tasas de formación de capital ${ }^{38}$. El concepto está suficientemente claro: el abaratamiento de los bienes de inversión en relación con el producto nacional implica que las mismas tasas de ahorro pueden generar una acumulación mucho mayor de capital físico. Esta misma idea intuitiva subyace al reciente estudio de J. Bradford De Long y L. Summers, que examinan el crecimiento económico de finales del siglo XX utilizando el método común del análisis macroeconométrico de corte transversal, enfoque fundamental para el debate actual sobre el crecimiento y la convergencia a largo plazo en la economía mundial ${ }^{39}$. Según Summers y De Long, la maquinaria y el equipo es una categoria de la formación de capital que tiene unos nexos especialmente poderosos con el crecimiento económico. Esta observación refuerza nuestro argumento, ya que las distorsiones de la economía argentina eran especialmente grandes en el caso de los bienes de equipo ${ }^{40}$.

Buscando la relación subyacente entre los precios de los bienes de capital, la inversión y el crecimiento, examinamos las relaciones entre los precios de los bienes de capital y la formación de capital en la economía mundial a lo largo del periodo 1960-1985. La evidencia econométrica de una gran muestra de países, aunando todos los datos de corte transversal, induce a pensar que los elevados precios relativos de los bienes de capital (RPK) están estrechamente relacionados con una baja proporción de inversión con respecto al PIB (CI). El cuadro 4 presenta regresiones que estiman la relación entre CI y RPK teniendo en cuenta el nivel de renta per cápita (YREL), la apertura de la economía (OPEN) y los efectos temporales (una variable ficticia por cada periodo quinquenal) ${ }^{41}$. La muestra elegida consiste en las medias de los sucesivos periodos

38 Williamson (1979), Williamson y Lindert (1980), cap. 12.

39 J. Bradford De Long y Lawrence Summers (1991).

40 Véase también Dowrick y Nguyen (1989). El trabajo más reciente de De Long (1992) integra Argentina en un análisis a muy largo plazo de las pautas de inversión y crecimiento económi. co a lo largo de todo el siglo XX y existen datos provisionales que parecen indicar que el crecimiento de Argentina es acorde con esta teoria.

41 En una investigación independiente contemporánea, Charles Jones (1992) identifica unas relaciones similares a las que analizamos aqui. Su estudio se refiere a la India, el mio a Argentina, paises ambos que son conocidos por su política intervencionista y sus estructuras de precios distorsionadas. Mi estudio se caracteriza por la utilización de un enfoque de datos de panel que nos permite explicar la evolución de las estructuras de precios a lo largo de varias décadas sin eliminar la información que aportan los datos por calcular promedios relativos a largos periodos, ya que las estructuras de precios y la demanda agregada de un pais varian mucho con el paso del tiempo. El problema de no dejar de lado demasiados datos y de no tratar al mismo tiempo de extraer demasiada información de series cronológicas que suelen elaborarse a partir de fechas de referencia irregularmente espaciadas es delicado. Pocas veces se realiza más de un censo cada diez años, y lo mismo sucede con los datos de referencia del IPC, por lo que es demasiado optimista utilizar una frecuencia anual. Optamos por las medias quinquenales, opción elegida tam- 
quinquenales comprendidos entre 1960 y 1984, excluidos los países cuyos niveles de renta per cápita representan menos de un 20 por ciento del americano ${ }^{42}$. La relación estimada es esencialmente una función de demanda de inversión que relaciona la proporción que representa la inversión con respecto al PIB y el precio relativo del capital y otras variables explicativas. Cabe considerarlo como un paso intermedio (estructural) subyacente al análisis (en forma reducida) de De Long y Summers, ya que centra la atención en el nexo existente entre el precio del capital y la inversión; en cambio, De Long y Summers centran la atención en el efecto final que producen (por separado) las tasas de inversión y el precio del capital en las tasas de crecimiento de la economía ${ }^{43}$. Las estimaciones son bastante sólidas: en todos los casos, el coeficiente de RPK es negativo, alrededor de -15 , y muy significativo, lo cual puede interpretarse de la manera siguiente: sería de esperar que en un país en el que el precio relativo del capital fuera un 10 por ciento superior al americano (RPK igual a 1,1 en lugar de 1,0) la proporción que representa la inversión con respecto al PIB (CI) fuera 1,5 puntos porcentuales más baja, ceteris paribus. En consonancia con la teoría convencional del crecimiento, el coeficiente de YREL es negativo y significativo; creo que eso quiere decir que los países más desarrollados cuya relación capital-trabajo es más alta tienen unos productos

bién por Brander y Dowrick (1993) en su investigación sobre la fecundidad y el crecimiento económico, otro estudio que confirma de nuevo el efecto de los precios relativos que analizamos aqui. Cardoso y Fishlow (1992) también prefieren las medias quinquenales en su investigación de las fuentes del crecimiento de Latinoamérica en la posguerra.

42 De Long y Summers (1991) omiten en su análisis esos países menos desarrollados, ya que esas son las observaciones cuya varianza parece ser más alta, lo que podría deberse al ruido o a un error de medición. Sostienen, además, lo siguiente:

Vemos, pues, con escepticismo la información que puede obtenerse combinando en una regresión paises muy pobres, que parecen tener unos niveles de productividad inferiores a los que disfrutaba Estados Unidos antes de la Revolución Industrial, con paises desarrollados tecnológicamente sofisticados. Centramos, pues, la atención especialmente en una muestra de países que tienen una productividad relativamente alta: los países cuyo PIB por trabajador era superior al de Estados Unidos en un 25 por ciento en 1960 (De Long y Summers, 1991, pág. 451).

De Long y Summers incluyen en su análisis 1960-85 como si fuera un periodo. Dado que utilizo un panel de medias quinquenales, aplico el mismo criterio en todos los periodos. Por lo tanto, mi muestra NOTPOOR incluye un pais en un determinado periodo sólo si YREI es superior a 25.

$43 \mathrm{Mi}$ ecuación es una relación macroeconómica agregada y no transmite información alguna sobre la conducta de empresas especificas a escala microeconómica. La oferta de ahorro también se considera exógena, por lo que se omite el precio del capital financiero, es decir, el tipo de interés. Estas omisiones no plantean problemas si los efectos del ahorro no están correlacionados con nuestras demás variables independientes, supuesto razonable cuando se trata de una muestra formada en gran medida por economias pequeñas y abiertas. Cavallo y Mundlak también suponen que el ahorro es exógeno en su exhaustivo estudio econométrico del crecimiento económico argentino basado en datos de series tempo. rales. Sin embargo, curiosamente omiten el precio relativo del capital como variable explicativa en las ecuaciones de la demanda de inversión (Cavallo y Mundlak, 1982, especialmente el cap. 8). 
marginales del capital más bajos y, por lo tanto, menos incentivos para invertir. En adelante, centraremos la atención en la regresión final que muestra la columna 4 , en la que se utilizan todas las variables explicativas, incluidas variables ficticias que recogen los efectos temporales ${ }^{44}$.

\section{CUADRO 4}

Inversión y precio relativo de los bienes de capital: resultados de las regresiones, $1960-84$

\begin{tabular}{|c|c|c|c|c|}
\hline & \multicolumn{4}{|c|}{ Variable dependiente CI. Muestra NOTPOOR } \\
\hline & (1) & (2) & (3) & (4) \\
\hline \multicolumn{5}{|l|}{ Coeficiente (estadístico $t$ ) } \\
\hline CONSTANTE & $\begin{array}{c}46,5 \\
(19,31)\end{array}$ & $\begin{array}{c}46,9 \\
(19,32)\end{array}$ & - & - \\
\hline RPK & $\begin{array}{l}-14,8 \\
(9,31)\end{array}$ & $\begin{array}{l}-14,7 \\
(9,27)\end{array}$ & $\begin{array}{l}-14,7 \\
(9,15)\end{array}$ & $\begin{array}{l}-14,6 \\
(9,05)\end{array}$ \\
\hline YREL & $\begin{array}{c}-0,0530 \\
(3,40)\end{array}$ & $\begin{array}{c}-0,0487 \\
(3,03)\end{array}$ & $\begin{array}{c}-0,0527 \\
(3,35)\end{array}$ & $\begin{array}{c}-0,0477 \\
(2,94)\end{array}$ \\
\hline OPEN & - & $\begin{array}{c}-0,0127 \\
(1,14)\end{array}$ & - & $\begin{array}{c}-0,0147 \\
(1,26)\end{array}$ \\
\hline $\begin{array}{l}\text { ¿Son significtivas las variables ficticias } \\
\text { temporales? } \ldots \ldots \ldots \ldots \ldots \ldots \ldots \ldots \ldots\end{array}$ & Omitidas & Omitidas & $\begin{array}{c}\mathbf{S i} \\
F(5,201)=73,7\end{array}$ & $\begin{array}{c}\mathrm{Si}_{\mathrm{i}} \\
F(5,200)=73,9\end{array}$ \\
\hline Grados de libertad & 205 & 204 & 201 & 200 \\
\hline$R^{2}$. & 298 & ,302 & ,302 &, 307 \\
\hline ETE & 6,65 & 6,64 & 6,69 & 6,68 \\
\hline Media de la variable dependiente ..... & 25,15 & 25,15 & 25,15 & 25,15 \\
\hline
\end{tabular}

Notas y fuentes: Los datos proceden de la Penn World Table Mark 5 (Summers y Heston, 1991). Se utilizan medias quinquenales de los periodos 1960-64, 1965-69, 1970-74, 1975-79, 1980-84. CI es la proporción que representa la inversión con respecto al PIB a precios internacionales corrientes (\%). RPK es el precio relativo del capital que se calcula dividiendo PI por P, donde PI es el nivel de precios de la inversión y $\mathrm{P}$ es el nivel de precios del PIB (tanto PI como P se expresan tomando como base E.E.U.U. $=100$ ). YREL es el nivel de PIB real per cápita (en relación con E.E.U.U. $=100$ ). OPEN es un indicador de la apertura y se calcula dividiendo las exportaciones más las importaciones por el PIB a precios internacionales corrientes. La muestra NOTPOOR comprende solamente las observaciones en las que YREL > 25.

${ }_{44}$ Obsérvese también que los efectos de la apertura parecen tener el signo incorrecto: las economias abiertas invierten menos según el cuadro 4 . Además, la apertura, además de ser bastante poco significativa en las regresiones, apenas contribuye a explicar las diferencias internacionales entre las proporciones de inversion. Este resultado es coherente con el hecho de que la apertura sólo sea una variable aproximada subóptima de una estructura de precios distorsionada con restricción de las importaciones, dandose el caso de que una variable que recoge una verdadera distorsión de los precios como RPK sea capaz de dar unos resultados mucho mejores. 
Parece que el precio relativo del capital ha influido significativamente en la demanda de inversión durante los últimos treinta años aproximadamente. Sin embargo, subsiste una cuestión: chasta qué punto fueron grandes esos efectos y en qué medida podrian explicar el lento crecimiento y las bajas tasas de formación de capital que se observaron tras la etapa peronista? La evidencia cuantitativa de la última Penn World Table confirma la pauta de variaciones de los precios que se observó en el mercado de capitales de Argentina durante la década de 1960 y que persistió incluso en la de $1970{ }^{45}$. Los datos inducen a pensar que aun teniendo en cuenta la apertura, la renta per cápita y los efectos temporales, el precio relativo argentino del capital (RPKRES) y la proporción que representa la inversión con respecto al PIB (CIRES) fueron, respectivamente, más de dos desviaciones típicas y media por encima y por debajo de la media mundial (cuadro $5(a))^{46}$, lo que supone un respaldo a las estimaciones de Díaz-Alejandro. La figura 5 lo muestra aún más claramente. El eje de abscisas mide el precio relativo del capital y el de ordenadas la proporción que representa la inversión con respecto al PIB (descontando en ambos casos la influencia de las demás variables). El gráfico de puntos dispersos es una correlación parcial de RPK y CI, una vez descontada la influencia de la apertura, la renta per cápita y los efectos temporales. Como es evidente, las observaciones de Argentina se agrupan perfectamente en la parte inferior derecha y cerca de la recta de regresión, lo que sugiere que la correlación de una RPK alta y una CI baja podría explicar correctamente la posición extrema que ocupa Argentina en el gráfico.

¿Puede explicar la excepcional estructura de precios de Argentina sus bajas tasas de formación de capital? El panel B del cuadro 5 indica que la mayor parte de la diferencia entre Argentina y otros paises en lo que se refiere a la $\mathrm{CI}$ se debe a la diferencia en lo que se refiere a la RPK ${ }^{47}$. De esta manera, la es-

45 Summers y Heston (1991).

to También se llega a esta misma conclusión incluso cuando se compara Argentina con varias submuestras de la economía mundial, y en un periodo de especial interés, los años 1960-64, que es el periodo de nuestra muestra más cercano a la administración Perón (cuadro 5, panel B). Las submuestras comprenden Norteamérica y Centroamérica (NCAM), Suramérica (SOAM), Asia, Europa (EURO), Oceanía (OCEA) y la OCDE. El valor característico de RPK en Argentina era, en esa época, de 2,2, casi el doble del nivel mundial (1.2) y mayor que todas las medias de las submuestras consideradas. Sudamérica (incluida Argentina), cuyo valor es 1,7, es la única submuestra que se aproxima. Si observamos ahora las proporciones de inversión, vemos que el nivel de $\mathrm{CI}$ era de 13,9 en Argentina, cifra muy inferior al nivel medio mundial de 25,1. El nivel de CI era superior a 20 en todas las submuestras, salvo en Sudamérica $(16,7)$. También se confirma la misma pauta: en Argentina los precios relativos de los bienes de capital son excepcionalmente altos y las tasas de inversión son excepcionalmente bajas.

47 Por ejemplo, Argentina tenía una proporción de inversión de 13,9 y el conjunto de la muestra una proporción de inversión de 25,1 , lo que representa una diferencia de 11,3 puntos en cuanto a RPK de $1,0(2,2$ menos una media mundial de 1,2$)$ multiplicada por un coeficiente 


\section{CUADRO 5}

\section{(A) La inversión y el precio relativo de los bienes de capital: estadísticas muestrales, 1960-84}

\begin{tabular}{|c|c|c|}
\hline & RPKRES & CIRES \\
\hline $\begin{array}{l}\text { A. Estadisticas de la muestra NOTPOOR una vez descontada la influencia } \\
\text { de la apertura, la renta per capita y los efectos temporales. }\end{array}$ & & \\
\hline Media & 0,000 & 0,000 \\
\hline Desviación tipica & 0,287 & 4,195 \\
\hline Media $+2,5 \times$ desviacion típica & 0,719 & 10,488 \\
\hline Media $-2,5 \times$ desviación típica & $-0,719$ & $-10,488$ \\
\hline \multicolumn{3}{|l|}{ B. Observaciones argentinas } \\
\hline Argentina 1960-64 & 0,904 & -11.947 \\
\hline Argentina $1965-69$ & 1,050 & $-14,953$ \\
\hline Argentina 1970.74 & 0,751 & $-12,310$ \\
\hline Argentina $1975-79$ & 0,934 & $-13,180$ \\
\hline Argentina $1980-84$ & 0,335 & $-11,856$ \\
\hline
\end{tabular}

(B) La inversión y el precio relativo de los bienes de capital: Argentina y el resto del mundo, 1960-64

\begin{tabular}{|c|c|c|c|c|c|c|c|c|}
\hline & $A R G$ & $A L L$ & $N C A M$ & SOAM & ASIA & EURO & $O C E A$ & $O E C D$ \\
\hline \multicolumn{9}{|c|}{ A. Estadísticas submuestrales de la muestra NOTPOOR, 1960-64 } \\
\hline OPEN & 10,9 & 39,6 & 32,7 & 22,2 & 57,9 & 43,9 & 27,2 & 38,8 \\
\hline RPK & 2,2 & 1,2 & 1,3 & 1,7 & 1,4 & 1,1 & 1,1 & 1,1 \\
\hline $\mathrm{CI}$. & 13,9 & 25,1 & 22,0 & 16,7 & 20,6 & 29,1 & 27,6 & 28,0 \\
\hline \multicolumn{9}{|c|}{ B. Argentina en comparación con la submuestra: explicación de la diferencia } \\
\hline $\begin{array}{l}\text { Diferencia observada entre las CI .. } \\
\text { Debida a las diferencias entre las }\end{array}$ & - & 11,3 & 8,1 & 2,9 & 6,7 & 15,3 & 13,8 & 14,1 \\
\hline $\begin{array}{r}\text { OPEN } \ldots \ldots \ldots \ldots \ldots \ldots \\
\text { Debida a las diferencias entre las }\end{array}$ & - & $-0,4$ & $-0,3$ & $-0,2$ & $-0,7$ & $-0,5$ & $-0,2$ & $-0,4$ \\
\hline RPK $\ldots \ldots \ldots \ldots$ & - & 14,0 & 13,0 & 7,1 & 11,7 & 16,5 & 15,6 & 16,0 \\
\hline Explicación de la DIFERENCIA & - & 13,6 & 12,7 & 7,0 & 11,0 & 16,0 & 15,4 & 15,6 \\
\hline$\%$ explicado $\ldots \ldots \ldots \ldots \ldots \ldots$ & - & $121 \%$ & $156 \%$ & $242 \%$ & $164 \%$ & $105 \%$ & $112 \%$ & $110 \%$ \\
\hline
\end{tabular}

NOTAS y FUENTES: Para las fuentes y las definiciones, véase el cuadro 4, RPKRES y CIRES son los residuos de las proyecciones de RPK y $\mathrm{CI}$ en función de un conjunto de variables formadas por OPEN, YREL y las variables ficticias temporales. La regresión de RPKRES en función de CIRES da los valores ajustados que se representan en la figura 5 y los correspondientes coeficientes y estadisticas sumarias de la columna 4 del cuadro 4 corregida para tener en cuenta los grados de libertad perdidos. Las diferencias entre las CI se obtienen restando de la CI de la submuestra la CI de Argentina. Las que se deben a las diferencias entre las OPEN es el coeficiente de OPEN de la columna 4 del cuadro 4 , multiplicado por las diferencias entre las OPEN (OPEN de la submuestra menos OPEN de Argentina). Lo mismo ocurre con las diferencias entre las RPK. Las submuestras son Norteamérica y Centroamérica (NCAM), Sudamérica (SOAM), Asia, Europa (EURO), Oceanía (OCEA) y la OCDE. 


\section{FIGURA 5}

La inversión y el precio relativo de los bienes de capital: correlación parcial, 1960-1984

Componente de la proporción que representa la inversión con respecto al PIB ortogonal a la apertura, la renta per capita y las variables ficticias temporales

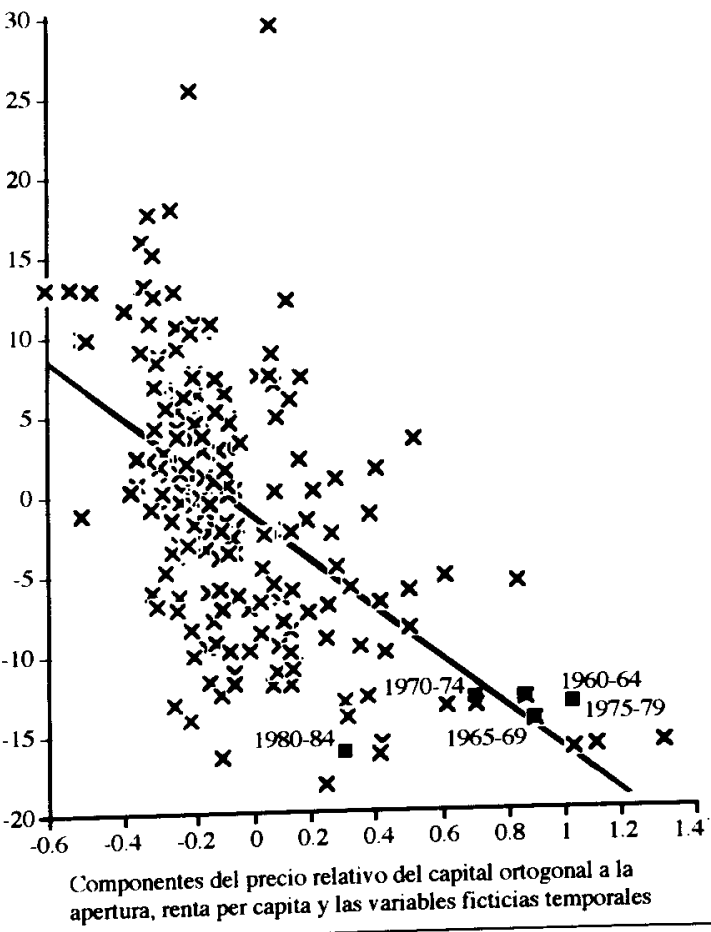

$\times$ Valores ajustados Valores reales

- Argentina

NOTAS: Véase el texto. Los puntos del gráfico corresponden a medias de periodos quinquenales. FuENTE: Columna 4 del cuadro 4 .

tructura de precios relativos explica con creces toda la diferencia entre la proporción de inversión de Argentina y la de otros países. La propia estructura de precios es el resultado directo de las prioridades de la política económica en un régimen intervencionista y sus consecuencias para el crecimiento económico fueron desastrosas:

del orden de 14- nos llevaria a predecir una diferencia en cuanto a la proporción de inversión de 14 puntos porcentuales, es decir, más de un 120 por ciento de la diferencia realmente observada. 
El enfoque que se ha presentado sugiere la siguiente visión sumaria de la política de crecimiento peronista. Desde alrededor de 1943 hasta 1953 se hicieron pocos esfuerzos por aumentar las exportaciones, al tiempo que no se prestó especial atención a la industria nacional de maquinaria y equipo... La formación de capital en [maquinaria y equipo] cayó en porcentaje del PNB y sus precios relativos subieron. El crecimiento económico resultó perjudicado, como consecuencia tanto de los escasos aumentos del capital físico como de la desaceleración de la tasa de absorción del cambio tecnológico plasmado en nueva maquinaria y equipo... Para mantener en pleno funcionamiento la capacidad existente en las industrias de bienes de consumo, la política económica redujo radicalmente las importaciones de nueva maquinaria... y, de hecho, se sacrificaron los objetivos fijados para la inversión y el crecimiento en aras de los objetivos fijados para el empleo y el consumo (a corto plazo) ${ }^{48}$.

Las implicaciones que tuvo esa estructura de precios distorsionada para el crecimiento económico sólo pueden examinarse de una manera aproximada, pero la figura 6 sugiere que los costes de los bienes de capital escasos en un régimen de sustitución de las importaciones no fueron insignificantes. En esta figura hemos estimado la desviación del precio del capital de Argentina con respecto al nivel de precios del PIB y hemos utilizado la diferencia para estimar el efecto producido en las tasas de inversión y en el crecimiento. Como sabemos, durante la mayor parte del periodo anterior a la Segunda Guerra Mundial, el precio del capital fue en Argentina entre un 50 y un 100 por ciento superior al nivel de precios del PIB. Esta diferencia de precios se traduce en una diferencia aproximada de 7-15 por ciento en lo que se refiere a la proporción que representa la inversión con respecto al PIB (las cifras se basan en la columna 4 del cuadro 4). Según las estimaciones de Dowrick y Nguyen $(1989,1.018$, cuadro 2, columna 2), el coeficiente de la proporción de inversión es de 0,064 en la regresión del crecimiento que realizan con la muestra de la $\mathrm{OCDE}$, lo que representa una tasa de inversión de 6,4 por ciento, cifra debidamente conservadora para nuestros fines ${ }^{49}$. Así pues, en el caso de Argentina,

48 Diaz-Alejandro (1970), pág. 347.

49 Según las estimaciones de Dowrick y Nguyen, la tasa de rendimiento de la muestra de la OCDE, salvo Japón, es de un 3,8 por ciento (Dowrick y Nguyen, 1989, pág. 1.018, cuadro 3, columna 2), pero sus estimaciones correspondientes a casi cualquier otra muestra son mucho más altas: utilizando los datos de la Penn World Table que comprenden los paises menos desarrollados, sus estimaciones de las tasas de rendimiento van desde un 11 por ciento hasta un 14 por ciento (cuadro 4). Según las estimaciones de un estudio posterior de Dowrick, realizado en colaboración con Brander, las tasas de rendimiento oscilan entre un 9 y un 11 por ciento en una muestra de 107 paises procedente de la Penn World Table; en el caso de una submuestra de 31 paises menos desarrollados, las estimaciones oscilan entre un 6 y un 7 por ciento y en el caso de una submuestra de 76 paises más desarrollados, oscilan entre un 8 y un 9 por ciento (Brander y Dowrick, 1993, cuadros 5-7). Los resultados de De Long y Summers correspondientes a una 
diriamos que las variaciones de la proporción que representa la inversión con respecto al PIB de 7-15 por ciento generarian unas variaciones de la tasa de crecimiento de $0,5-1,0$ por ciento. Esas variaciones son grandes: como indica la figura 6 , son de una magnitud suficiente para explicar alrededor de la mitad del lento crecimiento del PIB per cápita de Argentina en relación con la OCDE 50. Con este apoyo cuantitativo, el argumento de que el repliegue de $\mathrm{Ar}$ gentina y su adopción de una política de sustitución de las importaciones le costó muy caro en lo que se refiere al crecimiento sigue siendo tan convincente como siempre. Si se exploraran, además, las distorsiones existentes en la categoría de bienes de inversión, es posible que se observara que el efecto negativo producido por las distorsiones de los precios en el crecimiento ha sido aún más espectacular, lo que sugiere la necesidad de averiguar con mayor profundidad si se invirtió en los proyectos «equivocados» y, en caso afirmativo, con qué coste.

\section{Conclusiones}

Antes de concluir, conviene hacer algunas matizaciones. Las investigaciones sobre la historia económica cuantitativa argentina siguen siendo reducidas y limitadas por los escasos y frágiles datos; las explicaciones cuantitativas deben complementar y mantener en perspectiva los ricos análisis de los historiadores sociales, políticos e institucionales. En este artículo no hemos resuel-

muestra de 25 paises de elevada productividad en la posguerra sugieren que los rendimientos de la inversión están concentrados en las categorias de maquinaria y equipo y que esas tasas de rendimiento pueden ser increiblemente altas. Sus estimaciones indican que el rendimiento de esas categorias de inversión es como mínimo de un 30 por ciento, mientras que el de otras es insignificante (De Long y Summers, 1991, p. 458, panel superior). De Long ha ampliado el analisis a todo el siglo $\mathrm{XX}$ en el caso de un grupo más pequeño de países y ha observado unos efectos parecidos: alrededor de un rendimiento del 60 por ciento en el caso de la maquinaria y el equipo y un insignificante rendimiento del orden del 15 por ciento en el caso de otras categorias de inversion (De Long, 1992, p. 312). Cardoso y Fishlow (1992, pp. 203-5) obtienen tasas medias de rendimiento en la América Latina de la posguerra de 7-11 por ciento en el periodo 1950-80 en su conjunto. Aunque disminuyen con el paso del tiempo, son del orden de 6 por ciento en 1965 1975 y del orden de 20 por ciento en 1950-65. Todos estos resultados me inducen a pensar que mi utilización de la tasa de rendimiento de 6,4 por ciento de Dowrick y Nguyen es convenientemente conservadora para nuestros fines.

50 En la figura el área inferior representa el crecimiento medio de la renta per cápita de Argentina y la superior el crecimiento de la renta per capita de la OCDE. El área sombreada (la brecha de pérdida de crecimientol que se encuentra entre ellas estima el coste que tiene para el crecimiento el precio relativamente alto del capital en Argentina, calculado como acabamos de describir. 


\section{FIGURA 6}

El crecimiento de Argentina y la OCDE, 1929-1987:

el efecto de los elevados precios de los bienes de capital

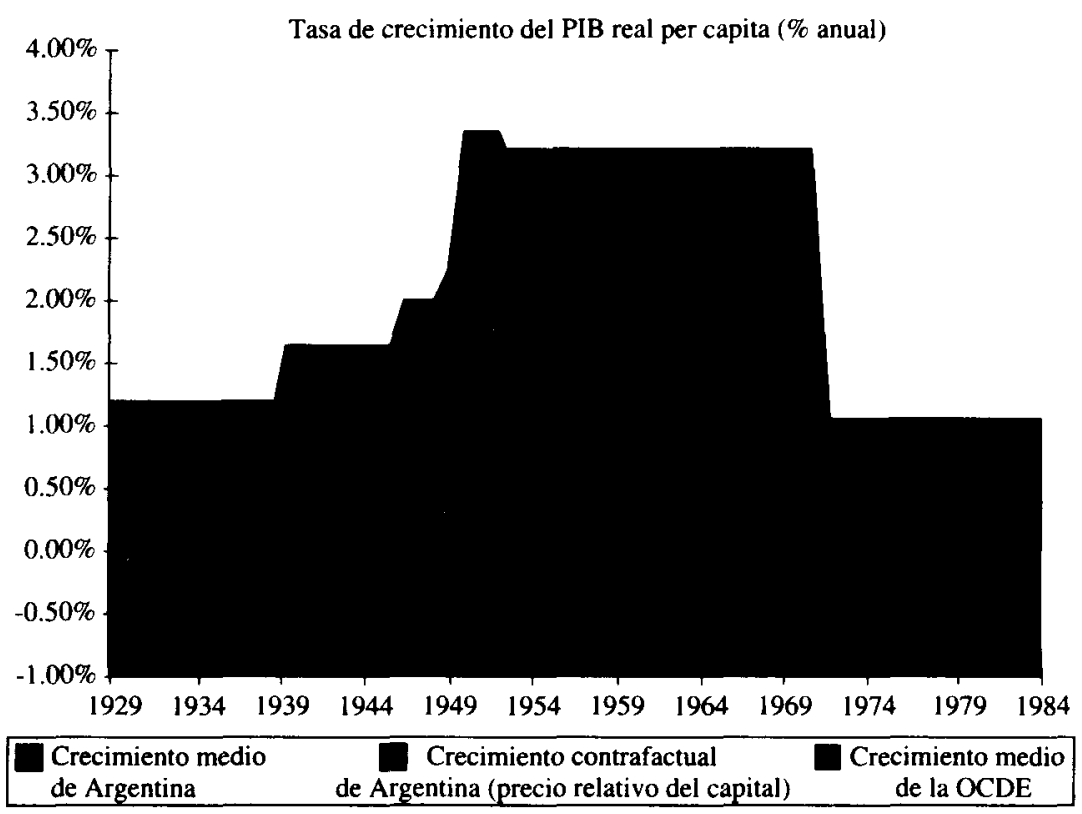

Notas: Véase el texto. El área sombreada de color negro representa el coste (crecimiento perdido, \% anual) provocado por la distorsión del precio del capital. El crecimiento contrafactual de Argentina procede de (a) el precio relativo del capital; (b) el coeficiente del precio relativo del capital en una regresión de la proporción de inversión; y (c) el coeficiente de la proporción de inversión en una regresión de la tasa de crecimiento.

FuENrEs: El crecimiento medio de OCDE y Argentina en 1929.50, $1950-73$ y 1973.87 procede de Maddison (1989, pág. 19). (a) un índice enlazado procedente de la fila 3 del cuadro 3 hasta 1960 o de la Penn World Table a partir de entonces (Summers y Heston, 1991); (b) $-14,6$, procede de la columna 4 del cuadro 4; (c) 6,4 por ciento, procede de Dowrick y Nguyen (1989, pág. 1.018, cuadro 3, columna 2).

to los problemas de datos, pero los hemos confrontado con una variada información procedente de diversas fuentes corroborantes: por ejemplo, la información sobre los tipos de interés frente a la información sobre las cantidades de los mercados de capitales del periodo de entreguerras; los datos sobre los precios posteriores a la Segunda Guerra Mundial de Diaz-Alejandro frente a las estimaciones de Summers y Heston de las mismas distorsiones. Los refinamientos y las extensiones de los datos primarios son ciertamente muy de- 
seables, pero los datos existentes concuerdan en general y ofrecen una descripción aún más clara de los resultados económicos argentinos, que hemos tratado de documentar y formalizar mejor.

Como ya se ha reconocido, este modesto trabajo trata de seguir la tradición de Díaz-Alejandro y, de hecho, se basa sobre todo en el estudio de la historia económica argentina. Aunque amplia su tesis de que la economía se vio atrapada por la intervención y las estrategias orientadas hacia el interior a partir de 1929, hemos tratado de mostrar que Argentina tuvo dificultades incluso desde la Primera Guerra Mundial y que el retraso la ha acompañado durante la mayor parte de este siglo. La explicación que ofrecemos no es una explicación monocausal del fracaso de Argentina: de hecho, no existe esa explicación (por lo tanto, es una explicación parcial y no se pretende que sea otra cosa). Sin embargo, trata de identificar un elemento fundamental: la acumulación de capital. Recapitulando, basta recordar cuán diferente era el mercado de capitales al que se enfrentó Argentina entre 1900 y la década de 1970, periodo en el que un floreciente mercado de capital generosamente surtido de financiación exterior dejó paso a dos regímenes sucesivos, cada uno con paralizantes obstáculos para la acumulación de capital: el primero limitado por la baja capacidad de ahorro en un clima de desintegración de los mercados mundiales de capital; el segundo limitado por una cara maquinaria en un clima de intervención del Estado.

En la primera fase (hasta 1913), el floreciente éxito de la Belle Époque argentina se debió en no poca medida a las espectaculares tasas de formación de capital, las cuales eran, a su vez, una faceta de la masiva exportación de capital de Gran Bretaña. En la segunda fase (desde 1913 hasta la década de 1930), la disminución de los préstamos exteriores hizo que las bajas tasas nacionales de ahorro limitaran, de hecho, la tasa alcanzable de acumulación de capital y la Argentina, caracterizada por su lento crecimiento, fue uno de los países que obtuvo peores resultados en la transición al periodo de entreguerras. En la tercera fase (desde la década de 1930 hasta la de 1950), las limitaciones impuestas por el ahorro disminuyeron, al tiempo que Argentina se replegó y adoptó una estrategia de sustitución de las importaciones y orientación hacia el interior. Como consecuencia, el precio relativo de los bienes de capital clave importados, sobre todo equipo y maquinaria, experimentó una subida suficientemente brusca para impedir la acumulación de capital. Ahora la inversión disminuyó no tanto como consecuencia de una restricción cuantitativa (relacionada con la oferta de ahorro) como por un cambio de los precios (relacionado con la oferta de bienes de capital). Los cálculos aproximados del PIB argentino contrafactural que se habría registrado si el precio del capital no hubiera estado distor- 
sionado inducen a pensar que al menos la mitad del retraso de Argentina en relación con la OCDE se debió a esos cambios de los precios registrados en el periodo 1950-73.

Afirmamos, pues, que el brusco deterioro de los resultados económicos relativos de Argentina puede atribuirse en gran parte al desfavorable clima existente a partir de 1913 para la acumulación de capital. La Belle Époque, aunque fue obra de los italianos y de los españoles que emigraron al río de la Plata, fue posible gracias a las abundantes entradas de capital británico; pero cuando se cerró este grifo, los argentinos no pudieron mantener el continuo ritmo de desarrollo que se había observado a principios de siglo: en primer lugar, porque no podian ahorrar bastante; en segundo lugar, porque, aunque pudieran, los precios reducian los incentivos para realizar las inversiones que son precursoras del crecimiento.

\section{BIBLIOGRAFIA}

Abreu, M. d. P. (1984): «Argentina y Brazil during the 1930s: The Impact of British and American International Economic Policies», en R. Thorp (ed.), Latin America in the 1930s: The Role of the Periphery in World Crisis, Nueva York, St. Martin's Press.

Baldwin, R. E. (1956): «Patterns of Development in Newly Settled Regions», ManchesterSchool, 24, p. 161-79.

BambRick, S. (1970): «Australia's Long-Run Terms of Trade», Economic Development and Cultural Change, 19, pp. 1-5.

BRANDER, J. A., y S. Dowrick (1993): «The Role of Fertility and Population in Economic Growth: Empirical Results from Aggregate Cross-National Datam, University of British Columbia, enero, mimeo.

Bulmer-Thomas, V. (1994): «The Latin American Economies in the 1930sm, en L. Bethell (comp.), The Cambridge History of Latin America, Cambridge, Cambridge University Press, vol. 6.

Bunge, A. E., y C. Garcta Mata (1931): «Argentina», en W. F. Willcox (comp.), International Migrations, Nueva York, National Bureau of Economic Research, 2 vols., vol. 2.

Butuin, N. G. (1962): Australian Domestic Product, Investment and Foreign Borrowing 1861 1938/39, Cambridge, Cambridge University Press.

Campa, J. M. (1990): «Exchange Rates and Economic Recovery in the 1930s: An Extension to Latin America», Journal of Economic History, 50, pp. 677-82.

Cardoso, E., y A. Fishlow (1992): «Latin American Development: 1950-1980m, en T. Halperin Donghi (ed.), The Colonial and Post-colonial Experience: Five Centuries of Spanish and Portuguese America, Journal of Latin American Studies, Quincentenary Supplement Cambridge, Cambridge University Press. 
Cavallo, D., y Y. MundlaK (1982): «Agriculture and Economic Growth in an Openonomy: The Case of Argentina», Research Report no. 36, International Food Policy Research Institute, diciembre.

CoRTÉs CONDE, R. (1992): «Export Led Growth in Latin America: 1870-1930», en T Halperin Donghi (comp.), The Colonial and Post-colonial Experience: Five Centuries of Spanish and Portuguese America, Journal of Latin American Studies, Quincentenary Supplement Cambridge, Cambridge University Press, 1992.

(1979): El progreso argentino, Buenos Aires, Editorial Sudamericana

ENoON, D. (1983): Settler Capitalism: The Dynamics of Dependent Development in the Soutbern Hemisphere, Oxford, Oxford University Press.

Diaz-Alejandro, C. F. (1970): Essays on the Economic History of the Argentine Republic, New Haven, Conn., Yale University Press.

- (1984a): «The 1940s in Latin America», en M. Syrquin, L. Taylor y L. E. Westphal (comps.), Economic Structure and Performance: Essays in Honor of Hollis B. Chenery, Orlando. Academic Press.

- (1984b): «Latin America in the 1930s», en R. Thorp (ed.), Latin America in the 1930s: The Role of the Periphery in World Crisis, Nueva York, St. Martin's Press.

(1985): «Argentina, Australia and Brazil Before 1929», en G. D. Tella y D. C. M Platt (eds.), Argentina, Australia and Canada: Studies in Comparative Development, 1870 1965, Londres, Macmillan.

- (1988): "No Less Than One Hundred Years of Argentine Economic History Plus Some Comparisons», en A. Velasco (ed.), Trade. Development and the World Economy: Selected Essays of Carlos F. Díaz-Alejandro, Oxford, Basil Blackwell.

Dowrick, S., y D.-T. NGUYEN (1989): «OECD Comparative Economic Growth 1950-85: Catch-Up and Convergence», American Economic Review, 79, pp. 1010-30.

Duncan, T., y J. Fogarty (1984): Argentina and Australia: On Parallel Paths, Carlton, Vic., Melbourne University Press.

Edelstein, M. (1981): «Foreign Investment and Empire 1860-1914», en R. Floud y D. McCloskey (comps.), The Economic History of Britain Since 1700, 2 vols., Cambridge, Cambridge University Press, vol. 2.

- (1982): Overseas Investment in the Age of High Imperialism, Nueva York, Columbia University Press.

Fogarty, J., E. Gallo y H. Diéguez (1977): «Argentina y Australia», Serie Verde, Jornadas $\mathrm{n}^{\circ}$ 201, Instituto Torcuato Di Tella, Buenos Aires.

Gerardi, R. E. (1985): «Australia, Argentina and World Capitalism: A Comparative Analysis 1830-1945», Transnational Corporations Research Project, Occasional Papers no. 8, Faculty of Economics, University of Sydney, mayo.

HALl, A. R. (comp.) (1968): The Export of Capital from Britain 1870-1914, Londres, Methuen.

Homer, S., y R. E. Sylla (1991): A History of Interest Rates, New Brunswick, Rutgers University Press, $3^{\mathrm{a}}$ ed.

IEERAL (Instituto de Estudios Económicos sobre la Realidad Argentina y Latinoamericana) (1986): «Estadísticas de la Evolución Económica de Argentina 1913-1984», Estudios, 9, julio/septiembre, pp. 103-184.

JONES, C. I. (1992): «Economic Growth and the Relative Price of Capital», MIT, febrero, (mimeo). 
Kindleberger, C. P. (1986): The World in Depression, 1929-1939, Berkeley, University of California Press.

Korol, J. C. (1991): «Argentine Development in a Comparative Perspective», Latin American Research Review, 26, verano, pp. 201-12.

DE Long, J. B. (1992), «Productivity Growth and Machinery Investment: A Long-Run Look», Journal of Economic History, 52, pp. 307-24.

- y L. H. Summers (1991): «Equipment Investment and Economic Growth», Quarterly Journal of Economics, 106, pp. 445-502.

Maddison, A. (1985): Two Crises: Latin America and Asia 1929-38 and 1973-83, Paris, OCDE.

- (1989): The World Economy in the 20tb Century, Paris, OCDE.

MCLEan, I. W. (1990): «Notes on Growth in Resource-Rich Economies», Harvard University, marzo (mimeo).

— (1991): «Saving in Settler Economies: Australian and North American Comparisons", University of Adelaide (mimeo).

Mitchell, B. R. (1980): European Historial Statistics, 1750-1975, Nueva York, Facts on File, $2^{\mathrm{a}}$ ed.

- (1983): International Historical Statistics: The Americas and Australasia, Detroit, Gale Research.

NuRKsE, R. (1954): «International Investment To-day in the Light of Nineteenth-Century Experience», Economic Journal, 64, pp. 744-58.

Della Paolera, G. (1988): «How the Argentine Economy Performed During the International Gold Standard: A Reexamination», tesis doctoral, University of Chicago, diciembre.

Peters, H. E. (1934): The Foreign Debt of The Argentine Republic, Baltimore, The Johns Hopkins Press.

Phelps, V. L. (1938): The International Economic Position of Argentina, Filadelfia, University of Pennsylvania Press.

PrebisCH, R. (1984): «Five Stages in My Thinking on Development», en G. M. Meier y D. Seers (eds.), Pioneers in Development, Nueva York, Oxford University Press. (1986): «Argentine Economic Policies Since the 1930s: Recollections», en G. D. Tella y D. C. M. Platt (eds.), The Political Economy of Argentina 1880-1946, Nueva York, St. Martin's Press.

Schedvin, C. B. (1990): «Staples and Regions of Pax Britannica», Economic History Review, 20, pp. 533-59.

Summers, R. y A. Heston (1991): «The Penn World Table (Mark 5): An Expanded Set of International Comparisons, 1950-1988», Quarterly Journal of Economics, 106, pp. 327-68.

TAYLOR, A. M. (1992): «External Dependence, Demographic Burdens and Argentine Economic Decline After the Belle Epoques, Joumal of Economic History, 52, pp. $907-36$.

— (1994): «Mass Migration to Distant Southern Shores», en T. J. Hatton y J. G. Williamson (eds.), Migration and the International Labor Market, 1850-1941, Londres, Routledge.

— y J. G. Williamson (1994): «Capital Flows to the New World as an Intergenerational Transfer», Journal of Political Economy, 102, abril, pp, 348-71.

Di Tella, G., y D. C. M. Platt (1985): Argentina, Australia and Canada: Studies in Comparative Development, 1870-1965, Londres, Macmillan, 1985. 
Di Tella, G., y M. Zymelman (1967): Las etapas del desarrollo económico argentino, Buenos Aires, Editorial Universitaria de Buenos Aires.

Di Tella, G., y M. Zymelman (1973): Los ciclos económicos argentinos, Buenos Aires, Editorial Paidós.

THORP, R. (1992): «A Reappraisal of the Origins of Import-Substituting Industrialisation: 1930-1950m, en T. Halperin Donghi (comp.), The Colonial and Post-colonial Experience: Five Centuries of Spanisb and Portuguese America, Journal of Latin American Studies, Quincentenary Supplement Cambridge, Cambridge University Press, 1992.

ToRnquist, E. \& Co., Limited (1919): The Economic Development of the Argentine Republic in the Last Fifty Years, Buenos Aires, Ernesto Tornquist \& Co., Limited.

Williamson, J. G. (1979): «Inequality, Accumulation, and Technological Imbalance: A Growth-Equity Conflict in Economic History?», Economic Development and Cultural Change, 27, pp. 231-54.

- (1991): «The Evolution of Global Labor Markets in the First and Second World Since 1830: Background Evidence and Hypotheses", Harvard Institute of Economic Research, Discussion Paper Series no. 1571, Harvard University, octubre.

- y P. H. LINDERT (1980): American Inequality: A Macroeconomic History, Nueva York, Academic Press.

Traducción de Esther Rabasco y Luis Toharia. 